\title{
The salt-responsive transcriptome of chickpea roots and nodules via deepSuperSAGE
}

Carlos Molina ${ }^{1,6^{*}}$, Mainassara Zaman-Allah³ ${ }^{3}$ Faheema Khan ${ }^{1,4}$, Nadia Fatnassi ${ }^{5}$, Ralf Horres ${ }^{1}$, Björn Rotter ${ }^{2}$, Diana Steinhauer ${ }^{2}$, Laurie Amenc ${ }^{3}$, Jean-Jacques Drevon ${ }^{3}$, Peter Winter ${ }^{2}$, Günter Kahl ${ }^{1}$

\begin{abstract}
Background: The combination of high-throughput transcript profiling and next-generation sequencing technologies is a prerequisite for genome-wide comprehensive transcriptome analysis. Our recent innovation of deepSuperSAGE is based on an advanced SuperSAGE protocol and its combination with massively parallel pyrosequencing on Roche's 454 sequencing platform. As a demonstration of the power of this combination, we have chosen the salt stress transcriptomes of roots and nodules of the third most important legume crop chickpea (Cicer arietinum L.). While our report is more technology-oriented, it nevertheless addresses a major world-wide problem for crops generally: high salinity. Together with low temperatures and water stress, high salinity is responsible for crop losses of millions of tons of various legume (and other) crops. Continuously deteriorating environmental conditions will combine with salinity stress to further compromise crop yields. As a good example for such stress-exposed crop plants, we started to characterize salt stress responses of chickpeas on the transcriptome level.
\end{abstract}

Results: We used deepSuperSAGE to detect early global transcriptome changes in salt-stressed chickpea. The salt stress responses of 86,919 transcripts representing 17,918 unique 26 bp deepSuperSAGE tags (UniTags) from roots of the salt-tolerant variety INRAT-93 two hours after treatment with $25 \mathrm{mM} \mathrm{NaCl}$ were characterized. Additionally, the expression of 57,281 transcripts representing 13,115 UniTags was monitored in nodules of the same plants. From a total of 144,200 analyzed 26 bp tags in roots and nodules together, 21,401 unique transcripts were identified. Of these, only 363 and 106 specific transcripts, respectively, were commonly up- or down-regulated (>3.0-fold) under salt stress in both organs, witnessing a differential organ-specific response to stress.

Profiting from recent pioneer works on massive cDNA sequencing in chickpea, more than 9,400 UniTags were able to be linked to UniProt entries. Additionally, gene ontology (GO) categories over-representation analysis enabled to filter out enriched biological processes among the differentially expressed UniTags. Subsequently, the gathered information was further cross-checked with stress-related pathways.

From several filtered pathways, here we focus exemplarily on transcripts associated with the generation and scavenging of reactive oxygen species (ROS), as well as on transcripts involved in $\mathrm{Na}^{+}$homeostasis. Although both processes are already very well characterized in other plants, the information generated in the present work is of high value. Information on expression profiles and sequence similarity for several hundreds of transcripts of potential interest is now available.

Conclusions: This report demonstrates, that the combination of the high-throughput transcriptome profiling technology SuperSAGE with one of the next-generation sequencing platforms allows deep insights into the first molecular reactions of a plant exposed to salinity. Cross validation with recent reports enriched the information about the salt stress dynamics of more than 9,000 chickpea ESTs, and enlarged their pool of alternative transcripts isoforms.

\footnotetext{
* Correspondence: carlos.molina@dijon.inra.fr

${ }^{1}$ Molecular BioSciences, Biocenter, Johann Wolfgang Goethe University, Max-

von-Laue-Str. 9, D-60439 Frankfurt am Main, Germany

Full list of author information is available at the end of the article
}

C Biomed Central

(c) 2011 Molina et al; licensee BioMed Central Ltd. This is an Open Access article distributed under the terms of the Creative Commons Attribution License (http://creativecommons.org/licenses/by/2.0), which permits unrestricted use, distribution, and reproduction in any medium, provided the original work is properly cited. 


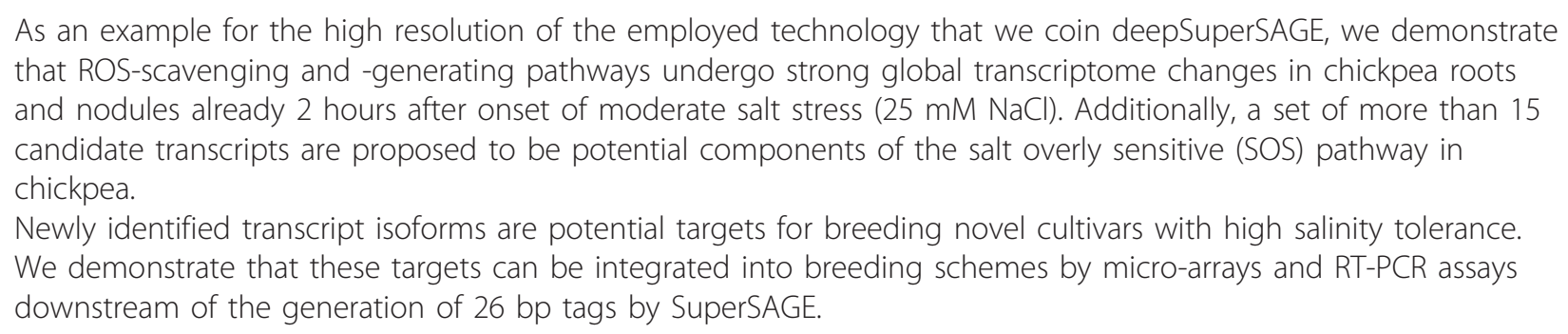

\section{Background}

High salinity, together with low temperatures and water stress, are responsible for the large margin existing between the potential yield in tons hectar ${ }^{-1}$ and the real harvest yield in several crops worldwide [1]. In semiarid agricultural areas of the world, soil salinization is tightly linked to the extensive use of artificial irrigation, which in combination with extended dry seasons, very quickly turns formerly productive areas practically into desserts [2]. In the future, this effect will even increase due to the high demand of water from other nonagriculture sectors (i.e. industry, overpopulated cities), whereas the possibilities to increase any crop's productivity through irrigation will necessarily decrease $[3,4]$. Despite the remarkable ability of plants to cope with a wide range of stresses, the race against the continuously deteriorating environmental conditions on our planet will be lost unless new plant breeding strategies for abiotic stress-tolerance are developed.

Chickpea, one of the most important staple food legume crops worldwide, is cultivated in regions considered to be "the eye of the hurricane" in view of the adverse conditions like poor-watered and saline soils (Mediterranean basin, Indian sub-continent) [5]. The increasing demand of production, and the adaptation of this crop to less appropriate, even poor soils, forces to study the high salinity response mechanisms of this important non-model plant.

Plants under salt stress have to battle against two severe impacts: i) the ionic disequilibrium, caused by the increased amount of sodium in the soil; and ii) the osmotic misbalance, in which the osmotic potential of the soil drastically decreases [6,7]. Additionally, the metabolic alterations and high demand of energy caused by the first two stresses are leading to a third and sometimes more lethal obstacle: the oxidative stress [8]. As a consequence, salinity tolerance is expected to depend on genes encoding proteins 1 ) limiting the rate of $\mathrm{Na}^{2+}$ uptake from the soil and managing its transport throughout the plant, 2) adjusting the ionic and osmotic balance of cells in roots and shoots, 3) regulating leaf development and the onset of senescence, and (4) controlling the overproduction of reactive oxygen species (superoxide $\left[\mathrm{O}_{2}{ }^{-}\right]$, hydrogen peroxide $\left[\mathrm{H}_{2} \mathrm{O}_{2}\right]$, and hydroxyl radicals $\left.\left[\mathrm{OH}^{-}\right]\right)$[9].

In model plants, extensive knowledge of biochemical and molecular processes underlying salt-stress responses has been accumulated over the past decades. Among several other striking advances in Arabidopsis thaliana, the signal transduction components of the salt overly sensitive pathway (SOS), a cascade activated by ionic disequilibrium, have been extensively characterized [10-13]. Further on, the activation of a specific saltresponsive MAP-kinase signalling cascade (the MKK2MPK4-MPK6 pathway) has been uncovered [14]. Several studies of calcium-dependent protein kinases (CDPKs), a kinase family linked to stress signalling, revealed the mechanisms of $\mathrm{Ca}^{2+}$ as messenger molecule in plants under stress alarm [15-17]. The dynamics of the transcriptome associated with ROS equilibrium (ROS production and detoxification) in plants has also been under intense scrutiny. For example, in Arabidopsis ROS-driven expression profiles on microarrays demonstrated that at least 8,000 , out of 26,000 evaluated transcripts, changed their expression level upon ROS induction [18].

In sharp contrast to the importance of chickpeas as staple food and industrial raw material, the saltresponses at the transcriptome and proteome levels had only been dealt with at very low throughput until some years ago, i.e. tens, or at the most, hundreds of genes had been considered $[19,20]$. In the last couple of years, massive sequencing approaches made it possible to gather information from thousands of complete ESTs, extending the available sequence information for previously under-studied organisms. For chickpea, a pioneer work has already started to uncover large portions of the transcriptome under abiotic stress, increasing the number of ESTs sequences deposited in the public domain up to more than 20,000 entries [21].

In the present work we profit from the high resolution power of SuperSAGE coupled to the Roche $454 \mathrm{Life} /$ APG GS FLX Titanium NGS technology to characterize the complete transcriptome of salt-stressed chickpea plants, especially at the onset of the stress. Here we report on 86,919 transcripts representing 17,918 unique 
$26 \mathrm{bp}$ tags from roots of the salt-tolerant variety INRAT93, 2 hours after $25 \mathrm{mM} \mathrm{NaCl}$-treatment. In parallel, the expression of 57,281 transcripts grouped in 13'115 UniTags was monitored in nodules of the same plants. Only a total of 363 and 106 transcripts, respectively, were commonly up- or down-regulated (>3.0-fold) under salt stress in both organs, suggesting a strong organ-specific differential response upon salt stress.

Using the information generated by recent massive cDNA sequencing in chickpea, more than 14,000 of the obtained 26 bp tags were validated by ESTs deposited in the public domain, adding valuable information in terms of i) their dynamics in the tested variety and under experimental conditions, ii) their differential expression in roots and nodules of the same plant towards salt stress, and iii) the existence of large sets of very similar alternative transcript isoforms detected in the form of SNPs-associated alternative tags (here denoted as SAATs) [22].

After EST-bridged UniTags annotation to Fabaceae and Arabidopsis mRNAs, more than 9,400 UniTags could be linked to UniProt entries. Further on, Gene ontology (GO) categories over-representation analysis enabled us to filter out enriched biological processes among the differentially expressed UniTags in chickpea roots and nodules under salt stress. Subsequently, the gathered information was cross-checked with stressrelated pathways for finer selection of potential transcripts of interest.

The vast amount of information generated here forced us to focus on transcripts associated with the generation and scavenging of reactive oxygen species as well as on transcripts associated with the maintenance of $\mathrm{Na}^{+}$ homeostasis, as example scenarios where intense transcriptome-remodelling is occurring after stress onset. Nevertheless the present work opens also several gates for the possible identification of new genes related to other pathways, and the incorporation of previously not stress-associated genes into the salt-stress context.

\section{Results}

\section{Abundance of 26 bp tags}

A total of $144,20026 \mathrm{bp}$ tags from roots $(86,919)$ and nodules $(57,281)$, respectively, of the salt-tolerant variety INRAT-93 were sequenced from untreated plants (control) and plants treated with $25 \mathrm{mM} \mathrm{NaCl}$ for $2 \mathrm{~h}$. After grouping the sequenced tags, a total of 17,918 and 13,115 unique transcripts (UniTags) were extracted from roots and nodules, respectively (excluding singletons). The expression profiles of 21,401 UniTags from both organs were revealed.

In roots, less than $1 \%$ percent of the 26 bp tags were present in very high copy numbers ( $>500$ copies $x$ $100,000^{-1}$ ), whereas $9 \%$ and $90 \%$ of the transcripts were present between 10 to 100 and less than 10 copies $\times$ $100,000^{-1}$, respectively. Similarly, in nodules of the same INRAT-93 plants, less than $1 \%$ of the transcripts were present in very high copy numbers ( $>500$ copies $\times$ $\left.100,000^{-1}\right)$. However, the number of transcripts in the different abundancy classes (10 to 100 , and less than 10 copies $\times 100,000^{-1}$ ) varied to some extent. Fifteen percent fell in between 10 and 100 copies $\times 100,000^{-1}$, contrasting the $10 \%$ found in roots. Transcripts detected in less than 10 copies $\times 100,000^{-1}$ made up $\sim 85 \%$ of the total 26 bp tags. UniTags from control and stress libraries were deposited in the Gene Expression Omnibus (GEO) public domain under the series GSE26638.

\section{EST-bridged annotation of UniTags: mutualism between two profiling techniques}

During the past years, the arrival of massive sequencing approaches enabled the sequencing of very large transcriptome portions for very favourable costs in relation to output. As a consequence, several groups have already started sequencing hundred thousands of complete cDNAs for species from which almost no sequence information was available. To prove the potential of combining the high quantitative resolution of a tagging technique with the high sequence quality obtained by large mRNA sequencing procedures, SuperSAGE libraries were annotated by linking UniTags to the more than 20,000 chickpea ESTs deposited in the public domain (plus additional 20,000 primary source sequences) [21]. After UniTag-linking, each EST sequence was re-annotated to Fabaceae and Arabidopsis databases obtained from NCBI (http://blast.ncbi. nlm.nih.gov) and TIGR (http://compbio.dfci.harvard.edu/).

From 21,401 UniTags (21,090 non-low complexity sequences), 14,423 found high homology matches with 8,837 chickpea ESTs. Through re-annotation of the ESTs to public databases, a total of 9,667 UniTags were assigned to 4,336 UniProt characterized entries. A total of 7,639 UniTags were linked to Gene Ontology (GO) terms (http://www.geneontology.org).

Concerning UniTag-to-EST representation, 6,283 out of 8,837 ESTs (71\%) were represented by a single UniTag, whereas 1,636 (18\%), 463 (5,2\%), 181 (2,0\%), 81 $(0,9 \%)$ and $193(2,18 \%)$ where represented by $2,3,4,5$ and $>5$ UniTags, respectively. Remarkably, the EST targeted by the largest number of UniTags was the Contig17642 (Q9LIN9_ARATH, 37 similar UniTags). For the total dataset, a positive correlation was found between the cumulative number of UniTag copies and the number of targeting UniTags for a given target EST (Figure 1). However, the distribution of copy numbers was not equal along all UniTags grouped to the same EST (families). Large families usually showed a single UniTag with high copy numbers accompanied by several similar tags found in much lower proportion (Figure 1). 


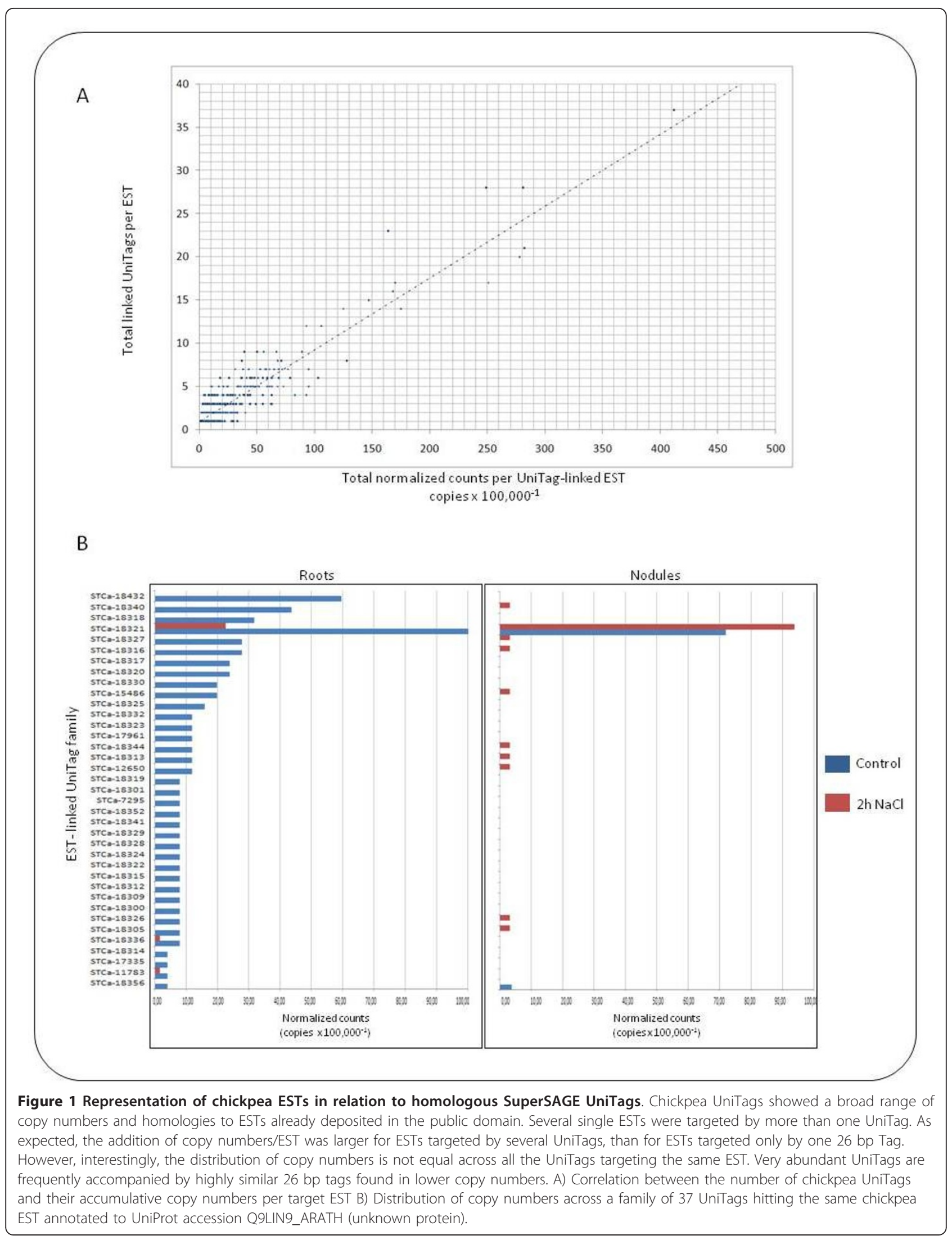


SNPs-associated alternative tags in SuperSAGE libraries

To assess the UniTags sequence similarity within chickpea SuperSAGE libraries without comparing to external ESTs, the datasets $\mathrm{Ca}-\mathrm{I} 93-\mathrm{NaCl}-\mathrm{Ct}$ and $\mathrm{Ca}-\mathrm{I} 93-\mathrm{NaCl}-\mathrm{Str}$ (control and salt-stressed roots, respectively) were selfBLASTed via stand alone BLAST [23]. Additionally, a SuperSAGE dataset from Musa acuminata (GPL2542) was retrieved from the gene expression omnibus (GEO, http://www.ncbi.nlm.nih.gov/geo) and self-BLASTed [24]. In this way, groups of UniTags sharing high sequence similarities were formed (excluding low complexity tags).

Along the three evaluated SuperSAGE datasets, $70 \%$ of the UniTags did not find high homologies ( $>22 \mathrm{bp}$ ) to any other UniTag within the own library (Figure 2). In much lower proportions, 15 , 4, and $2 \%$ of the UniTags, found one, two, and more than three similar hits, respectively, within the own libraries. Several of the similar UniTags belonging to the same family were differentiated by SNPs, a phenomenon already reported for humans, and known as SNPs-associated alternative tags (here denoted as, SAATs) [22]. An example of a large SAAT family of chickpea UniTags is depicted in Figure 2.

\section{Diversity of expression profiles along SAATs}

As exemplified in Figure 2 through a family of 26 UniTags annotated to a histone H3 protein (A5BX39_VITVI), UniTags associated to the same SAAT family very often showed different expression profiles and a very different distribution of copy numbers. For the exemplified case, UniTag STCa-8217 showed the largest number of copies in all four libraries with a total of $2,026.78$ copies $\times$ $100,000^{-1}$, whereas the remaining 25 UniTags only added up to 316.47 copies $\times 100,000^{-1}$. Remarkably, the majority of significant expression changes are seen in low copy number UniTags. The present result emphasizes the complementarities of both SuperSAGE and other massive sequencing approaches. In SuperSAGE libraries all sequencing efforts are directed to a discrete region of a given EST, thus gaining on resolution in a determined region, however, sacrificing the larger coverage that could be obtained through larger reads (e.g. RNAseq libraries).

\section{Stress- and organ-related differential gene expression in chickpea roots and nodules}

In roots of the salt-tolerant chickpea variety INRAT-93, $35 \%$ of the 26 bp tags were at least 2.7 -fold up- or down-regulated $\left[R_{(\ln )}>1.0\right]$, respectively, after only 2 hours of exposure to $25 \mathrm{mM} \mathrm{NaCl}$. From these, more than 2,000 tags (11\%) were at least 8-fold down-regulated, a much higher proportion than the mere $1.93 \%$ (346 tags) showing more than 8-fold up-regulation in the same organ, and also, far more than the 0.55 and 0.73\% (72 and 9626 bp tags, respectively) showing at least 8-fold down- or up-regulation in nodules of the same plants. With the highest up-regulation level, a $26 \mathrm{bp}$ tag annotated to a putative basic PR1 precursor (Q3LF77_PEA) was highly induced and most differentially expressed $\left(\mathrm{R}_{\mathrm{ln}}=4.34,>70\right.$-fold induced). An early nodulin class 40 (Enod40, NO40_SESRO) showed the second highest induction level. This is the first report of a dramatic induction of an Enod40 gene in legumes under salt-stress. Apart from its function in the early stages of nodule formation, Enod40s may also modulate the action of auxin, and function as plant growth regulators altering phytohormone responses (http://www.uniprot.org/uniprot/O24369) [25].

The top 40 salt stress up-regulated transcripts from chickpea roots are deposited in Table 1. GO slim (biological process) statistics for the corresponding UniProt accessions are depicted in Figure 3.

Among the GO slim terms (biological processes) linked to the most up-regulated root UniTags, oxidation-reduction occupied the highest rank, being represented by transcripts annotated to Q9ZNQ4_CICAR (Superoxide dismutase), Q9XER2_TRIRP (1-aminocyclopropane-1-carboxylate oxidase), Q9SML1_CICAR (Cytochrome P450 monooxygenase), B7Z177_PEA and Q43817_PEA (Lipoxygenases), Q84KA1_CROSA (Alternative oxidase), and Q40310_MEDSA (Chalcone reductase). Although not directly oxidation-reduction related, cellular ketone metabolic process was added to this group through association with lipoxygenases reported above and the accession Q8W1A0_SOYBN (Cysteine synthase). Further on, the translation biological process was represented by A9TXV0_PHYPA (predicted protein), Q84U89_MEDSA (60S ribosomal protein), Q7X9K1_WHEAT (Ribosomal Pr 117), and RLA1_MAIZE (60S acidic ribosomal protein). These results suggest a strong activation of ROS-scavenging mechanisms, a very well known event in stressed plant tissues, and deploy of the protein machinery as prime responses in the stressed roots. However, information based on only the top 40 up-regulated UniTags should not be considered as representative for the whole transcriptome. In subsequent sections, representation-analysis of GO terms, that take the expression level of the complete set of annotated UniTags into account, will be assessed.

Simultaneously with the analysis of whole-transcriptome responses to salt stress in roots, nodules of the same plants were separately harvested for the establishment of SuperSAGE libraries (control and $2 \mathrm{~h} 25 \mathrm{mM}$ $\mathrm{NaCl}$-treatment, respectively). In contrast to saltstressed chickpea roots (346 UniTags up-, 2055 downregulated), only 95 and 72 UniTags, respectively, were at least 8.0-fold up- or down-regulated. The top 40 most up-regulated transcripts in chickpea nodules after 2 hours of salt stress are listed in Table 2. GO slim 
A

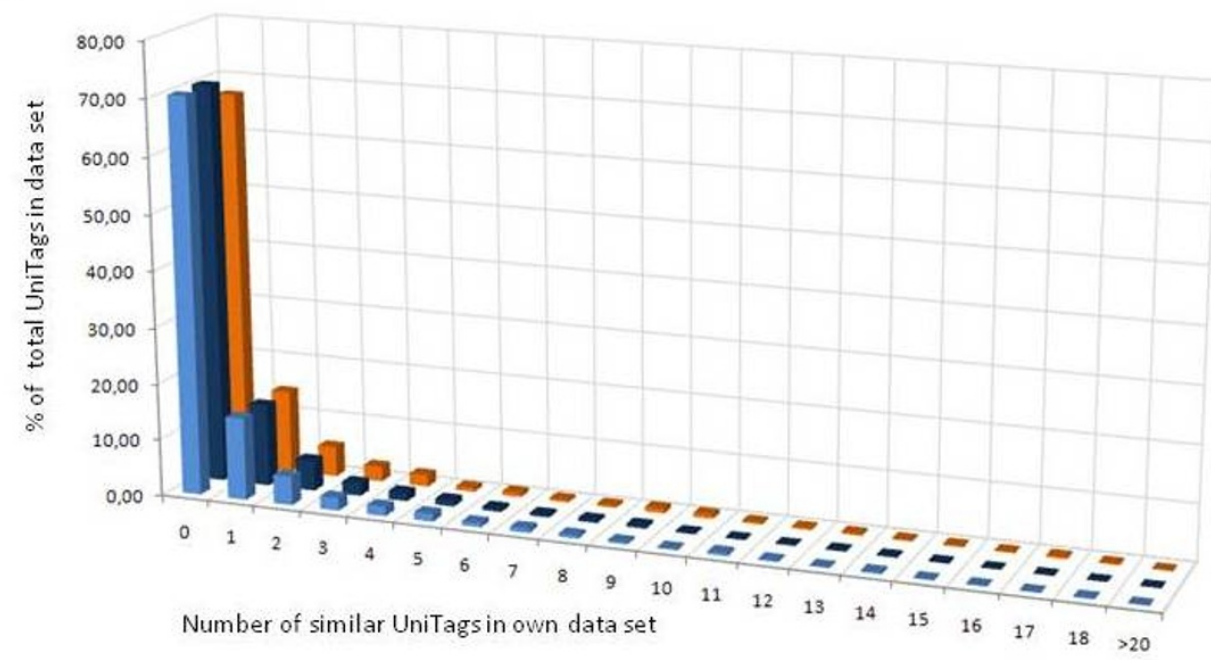

II93 Root Ctrl

- 193 Root $\mathrm{NaCl}$

Musa sp

B

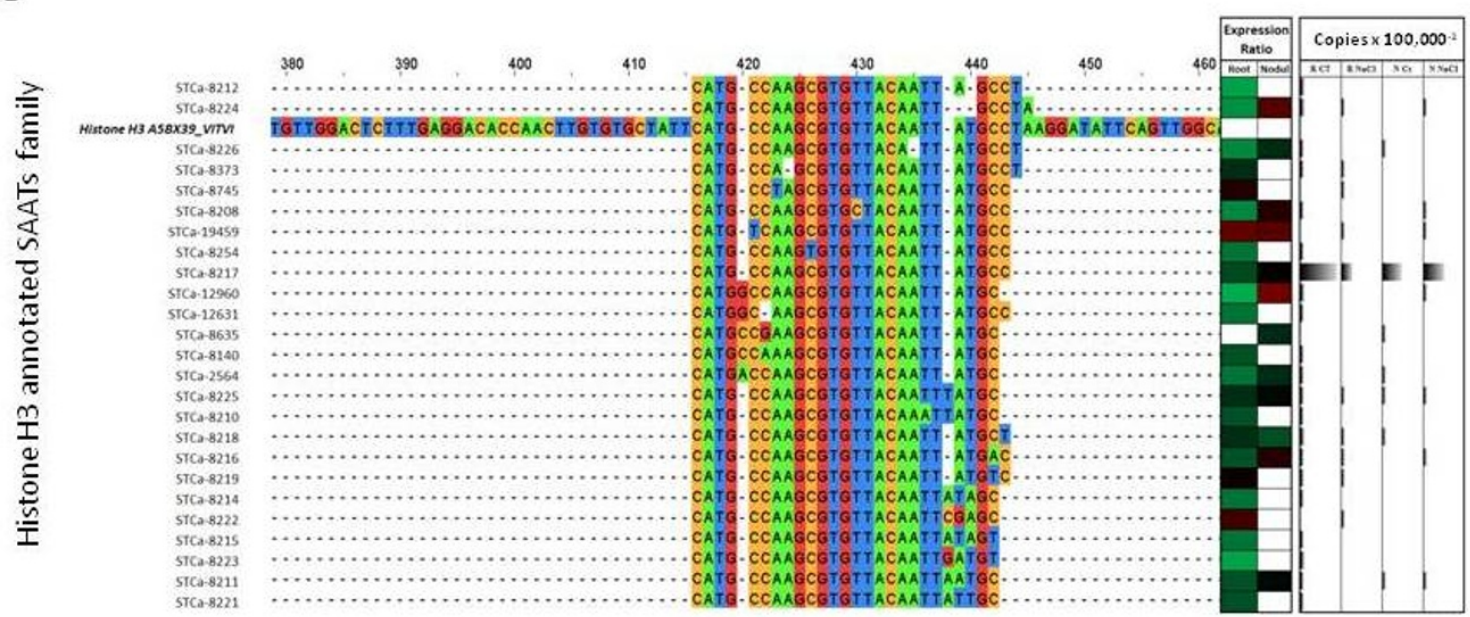

Figure 2 Occurrence of highly similar UniTags within deepSuperSAGE libraries. A) Proportion of similar hits found after BLASTing any given UniTag against its own SuperSAGE library. Three sources of UniTags were compared, comprising two chickpea SuperSAGE libraries and a Musa acuminata SuperSAGE library deposited in the public domain. Almost 70\% of the UniTags do not find similar hits, whereas 30\% can find more than one similar UniTag within the own library B) Example of a family of very similar UniTags annotated to a histone H3 UniProt entry. Several of the UniTags are differentiated by SNPS, and represent so called SNP-associated alternative tags (SAATs) families. Large copy number differences can be observed among very similar UniTags (graphically represented in the right panel).

(biological process) statistics for the corresponding UniProt accessions are depicted in Figure 3.

In comparison to roots of the same plants, highly expressed nodule transcripts originated from genes encoding TFs and transport-related proteins. Among the represented GO slim biological process in the most 40 upregulated UniTags in salt stressed nodules (Figure 3), transcription and regulation of biological processes were represented by the UniProt entries ELOF1_ARATH (Transcript elongation factor 1), C7AFG1_CICAR (NAC family transcription factor 4), Q2PJR9_SOYBN (WRKY27 transcription factor), and PHYA_PEA (Phytochrome A). The response to stimulus process was also represented by accessions like F10AL_ARATH (FAM10 family protein) and HSP12_MEDSA (18.2 kDa class I heat shock protein). Further on, translation process was in turn represented by 
Table 1 Top 40 salt stress up-regulated annotatable UniTags from INRAT-93 roots

\begin{tabular}{|c|c|c|c|}
\hline Tag ID & Protein & Fold change & Uniprot ID \\
\hline STCa-16261 & Putative basic PR1 precursor & 77,09 & Q3LF77_PEA \\
\hline STCa-18884 & Early nodulin & 60,95 & NO40_SESRO \\
\hline STCa-19168 & Lipoxygenase & 49,50 & Q43817_PEA \\
\hline STCa-7896 & Superoxide dismutase & 40,57 & Q9ZNQ4_CICAR \\
\hline STCa-318 & Trypsin protein inhibitor 3 & 36,13 & Q5WM51_CICAR \\
\hline STCa-5894 & General substrate transporter & 34,09 & A2Q5Z1_MEDTR \\
\hline STCa-21968 & Aquaporin & 34,09 & Q8W4T8_MEDTR \\
\hline STCa-5877 & Alternative oxidase & 30,85 & Q84KA1_CROSA \\
\hline STCa-19021 & Extensin & 30,02 & O65760_CICAR \\
\hline STCa-17087 & Dormancy-associated protein & 29,22 & O22611_PEA \\
\hline STCa-283 & Plastid phosphate translocator & 27,58 & A3RLBO_VICNA \\
\hline STCa-7166 & Isocitrate dehydrogenase (NADP) & 25,97 & IDHP_MEDSA \\
\hline STCa-10582 & Chalcone reductase & 25,97 & Q40310_MEDSA \\
\hline STCa-6410 & Predicted protein & 25,56 & A9V7Z1_MONBE \\
\hline STCa-24417 & Lipoxygenase & 24,34 & B7Z177_PEA \\
\hline STCa-1381 & Acetyl CoA synthetase & 24,34 & Q8LPV1_DESAN \\
\hline STCa-2982 & Cysteine synthase & 23,52 & Q8W1A0_SOYBN \\
\hline STCa-24330 & $\mathrm{ABC}$ transporter & 21,91 & O28298_ARCFU \\
\hline STCa-20215 & Putative extracellular dermal glycoprotein & 21,91 & Q9FSZ9_CICAR \\
\hline STCa-13750 & Glucose/galactose transporter & 21,09 & Q87CB9_XYLFT \\
\hline STCa-22299 & Predicted protein & 20,70 & A9TXV0_PHYPA \\
\hline STCa-21916 & Mob1-like protein & 20,70 & Q2WBN3_MEDFA \\
\hline STCa-20066 & 14-3-3-like protein & 20,70 & A5YM78_CICAR \\
\hline STCa-18427 & Ribosomal Protein 117 & 20,29 & Q7X9K1_WHEAT \\
\hline STCa-24398 & 40 S ribosomal protein $\mathbf{S} 25$ & 20,29 & RS25_SOLLC \\
\hline STCa-23821 & ADP-ribosylation factor & 20,29 & Q6S4R7_MEDSA \\
\hline STCa-1885 & Mob1-like protein & 19,47 & Q2WBN3_MEDFA \\
\hline STCa-387 & CPRD49 protein & 19,47 & Q9AYM5_VIGUN \\
\hline STCa-22950 & Rubber elongation factor & 19,47 & Q2HUF4_MEDTR \\
\hline STCa-21993 & Isoliquiritigenin 2'-O-methyltransferase & 19,47 & CHOMT_MEDSA \\
\hline STCa-17434 & Chitinase-related agglutinin & 18,67 & A1YZD2_ROBPS \\
\hline STCa-20130 & Pectinesterase & 17,85 & Q2HRX3_MEDTR \\
\hline STCa-23784 & Predicted protein & 17,85 & Q2GRIO_CHAGB \\
\hline STCa-4531 & Cytochrome P450 monooxygenase & 17,85 & Q9SML1_CICAR \\
\hline STCa-22619 & Predicted protein & 17,85 & A9SIK2_PHYPA \\
\hline STCa-4616 & 605 ribosomal protein & 17,05 & Q84U89_MEDSA \\
\hline STCa-10115 & Cytochrome b561 & 17,05 & A2Q4A8_MEDTR \\
\hline STCa-12309 & Probable methyltransferase & 17,05 & PMTQ_ARATH \\
\hline STCa-1385 & 1-aminocyclopropane-1-carboxylate oxidase & 17,05 & Q9XER2_TRIRP \\
\hline STCa-14437 & 605 acidic ribosomal protein P1 & 17,05 & RLA1_MAIZE \\
\hline
\end{tabular}

A9TXV0_PHYPA (predicted protein), and Q3LUM5_GOSHI (Elongation factor 1-alpha), whereas transport was represented by Q94FN1_LOTJA (Phosphatidylinositol transfer-like protein III), PMA9_ARATH (ATPase 9), NLTP_CICAR (Non-specific lipid-transfer protein precursor), A2Q5Z1_MEDTR (General substrate transporter), and Q762A5_ORYSJ (BRI1-KD interacting protein 109).

In addition to the expression profiles under stress conditions, differentially expressed UniTags in non-stressed nodules versus non-stressed roots from the same INRAT-93 plants were as well detected. A total of 51,545 tags from both untreated libraries represented 11,525 different UniTags. A total of 7,941 UniTags showed >3.0fold differential expression between both organs. Of these, 2,098 UniTags with >3.0-fold differential expression were more prevalent in nodules. With a higher threshold, 140 transcripts were more than 8.0-fold prevalent in the symbiotic organs. All organ- and stress-related 


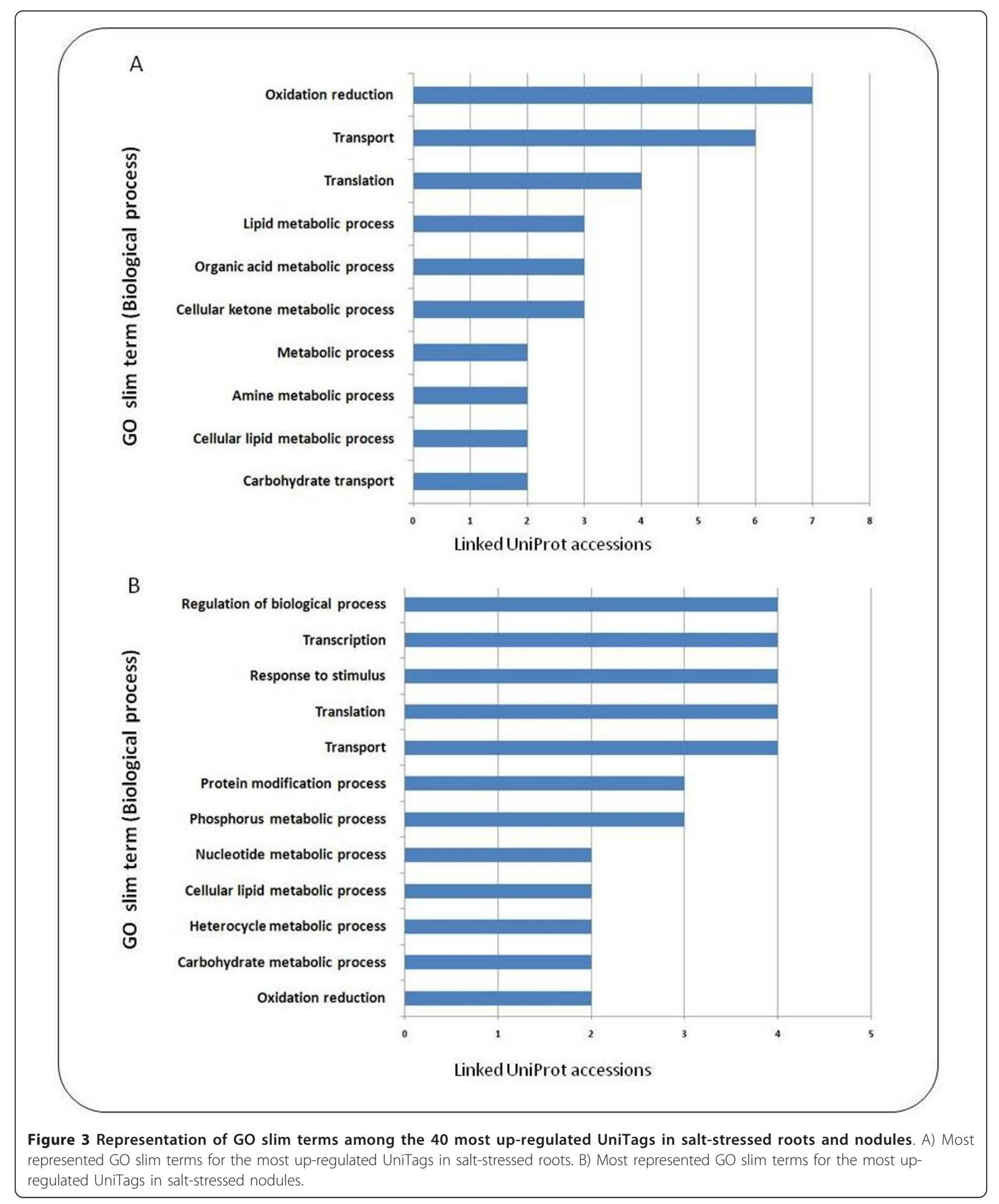


differentially expressed UniTags along with their respective annotations are deposited in Additional file 1.

Setting a minimum threshold of 3 -fold differential expression, from the 2,098 26 bp tags prevalent in non-stressed nodules, 515 (24.5\%) were also at least 3-fold up-regulated in roots under salt stress. These 515 UniTags represented $23.3 \%$ of the root transcripts $>3$-fold up-regulated by salt. On the other hand, only 10 out of the 2,098 UniTags were more than 3-fold up-regulated in salt-stressed nodules. In both salt-stressed roots and nodules, 363 common 26 bp tags were more than 3 -fold up-regulated (16.7\% from nodules, and $16.4 \%$ from roots; Figure 4, upper panel). As far as down-regulation is concerned, 1,729 out of 1,936 UniTags prevalent in non-stressed roots were more than 3fold down-regulated in roots after $2 \mathrm{~h}$ of salt treatment. A total of 275 tags were commonly more than 3 -fold downregulated in both roots and nodules under salt-stress.

If the threshold is set to 8-fold differential expression, 37 out of 140 tags prevalent in non-stressed nodules were more than 8-fold up-regulated in salt-stressed roots. Upon

Table 2 Top 40 up-regulated annotatable UniTags in salt stressed nodules

\begin{tabular}{|c|c|c|c|}
\hline Tag ID & Protein & Fold induction & Uniprot ID \\
\hline STCa-18884 & Early Nodulin & 61,44 & NO40_SESRO \\
\hline STCa-11090 & $40 S$ ribosomal protein SA & 15,36 & RSSA_CICAR \\
\hline STCa-5362 & $18.2 \mathrm{kDa}$ class I heat shock protein & 13,65 & HSP12_MEDSA \\
\hline STCa-22299 & Predicted protein & 13,65 & A9TXVO_PHYPA \\
\hline STCa-17434 & Chitinase-related agglutinin (Fragment) & 13,65 & A1YZD2_ROBPS \\
\hline STCa-2116 & Syringolide-induced protein B13-1-9 & 13,65 & Q8S8Z8_SOYBN \\
\hline STCa-9450 & ATPase 9 & 13,65 & PMA9_ARATH \\
\hline STCa-13463 & Formin 121 isoform & 13,65 & Q8H1H2_SOLLC \\
\hline STCa-24417 & Lipoxygenase & 12,79 & B7Z177_PEA \\
\hline STCa-5357 & Phosphatidylinositol transfer-like protein III & 11,94 & Q94FN1_LOTJA \\
\hline STCa-89 & Cold-induced protein & 11,94 & Q6PNN7_9FABA \\
\hline STCa-15605 & BRI1-KD interacting protein 109 & 11,94 & Q762A5_ORYSJ \\
\hline STCa-8350 & Isopentenyl pyrophosphate isomerase & 11,94 & Q6EJD1_PUELO \\
\hline STCa-5037 & Phytochrome A & 11,94 & PHYA_PEA \\
\hline STCa-175 & Transcription elongation factor 1 homolog & 10,24 & ELOF1_ARATH \\
\hline STCa-7855 & Abnormal suspensor SUS2 & 10,24 & UPI000016331D \\
\hline STCa-705 & MAP kinase protein & 10,24 & Q9SMJ7_CICAR \\
\hline STCa-2196 & SRC2 & 10,24 & O04133_SOYBN \\
\hline STCa-6099 & Pyruvate kinase & 10,24 & Q5F2M7_SOYBN \\
\hline STCa-305 & FAM10 family protein & 10,24 & F10AL_ARATH \\
\hline STCa-10862 & Os04g0591100 protein & 10,24 & QOJAL2_ORYSJ \\
\hline STCa-933 & Major histocompatibility class I receptor & 10,24 & Q95197_9PERO \\
\hline STCa-13055 & Non-specific lipid-transfer protein precursor & 10,24 & NLTP_CICAR \\
\hline STCa-6059 & Protein RIK & 10,24 & RIK_ARATH \\
\hline STCa-15235 & L3 Ribosomal protein & 10,24 & Q9SBR8_MEDVA \\
\hline STCa-20520 & Elongation factor 1-alpha & 10,24 & Q3LUM5_GOSHI \\
\hline STCa-11119 & Fiber annexin & 10,24 & O82090_GOSHI \\
\hline STCa-1896 & Protein kinase-like protein & 9,38 & Q56YK2_ARATH \\
\hline STCa-19301 & F-box/kelch-repeat protein & 8,53 & FBK22_ARATH \\
\hline STCa-5894 & General substrate transporter & 8,53 & A2Q5Z1_MEDTR \\
\hline STCa-5877 & Alternative oxidase & 8,53 & Q84KA1_CROSA \\
\hline STCa-1885 & Mob1-like protein & 8,53 & Q2WBN3_MEDFA \\
\hline STCa-170 & Mob1-like protein & 8,53 & Q2WBN3_MEDFA \\
\hline STCa-16125 & Cytochrome c oxidase subunit $6 \mathrm{~b}$ & 8,53 & Q8LD51_ARATH \\
\hline STCa-8434 & Fiber protein Fb2 & 8,53 & Q8GT87_GOSBA \\
\hline STCa-18178 & Histone H2A.2 & 8,53 & H2A2_MEDTR \\
\hline STCa-2067 & NAC family transcription factor 4 & 8,53 & C7AFG1_CICAR \\
\hline STCa-9977 & T1K7.26 protein & 8,53 & Q9FZC2_ARATH \\
\hline STCa-4833 & WRKY27 & 8,53 & Q2PJR9_SOYBN \\
\hline STCa-11765 & Putative uncharacterized protein & 8,53 & A2Q3F3_MEDTR \\
\hline
\end{tabular}




\begin{tabular}{|c|c|c|c|c|c|c|c|c|}
\hline \multicolumn{3}{|c|}{ 3.0-fold } & \multicolumn{2}{|c|}{$\begin{array}{c}25 \mathrm{mM} \text { NaCl-treated } \\
\text { roots }(2 \mathrm{~h})\end{array}$} & \multicolumn{2}{|c|}{$\begin{array}{c}\begin{array}{c}\text { Non-stressed } \\
\text { nodules vs roots }\end{array} \\
\text { nod }\end{array}$} & \multicolumn{2}{|c|}{$\begin{array}{l}25 \mathrm{~mm} \mathrm{NaCl} \text {-treated } \\
\text { nodules (2h) }\end{array}$} \\
\hline & & & $\begin{array}{l}\text { Up: } \\
\text { regulated }\end{array}$ & $\begin{array}{l}\text { Downt- } \\
\text { reguated } \\
\end{array}$ & $\begin{array}{l}\text { Nodule: } \\
\text { prevalent }\end{array}$ & $\begin{array}{c}\text { Root- } \\
\text { prevalent }\end{array}$ & $\begin{array}{c}\text { Up: } \\
\text { regulated } \\
\end{array}$ & $\begin{array}{c}\text { Down- } \\
\text { regulated }\end{array}$ \\
\hline & & Total & 2,207 & 3,938 & 2,098 & 1,936 & 2,162 & 1,384 \\
\hline \multirow{2}{*}{ 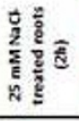 } & up-regulated & 2,207 & & & 515 & 6 & 363 & 106 \\
\hline & $\begin{array}{l}\text { Down: } \\
\text { regulated } \\
\end{array}$ & 3,938 & & & 24 & 1,729 & 204 & 275 \\
\hline \multirow{2}{*}{ 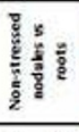 } & $\begin{array}{l}\text { Nodule. } \\
\text { prevalent }\end{array}$ & 2,098 & 515 & 24 & & & 10 & 901 \\
\hline & $\begin{array}{c}\text { Root- } \\
\text { prevatent }\end{array}$ & 1,936 & 6 & 1,729 & & & 174 & 17 \\
\hline \multirow{2}{*}{ 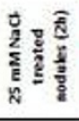 } & Up-regulated & 2,162 & 363 & 204 & 10 & 174 & & \\
\hline & $\begin{array}{l}\text { Down- } \\
\text { regulated } \\
\end{array}$ & 1,384 & 106 & 275 & 901 & 17 & & \\
\hline \multirow{3}{*}{\multicolumn{2}{|c|}{8.0 -fold }} & & \multicolumn{2}{|c|}{$\begin{array}{l}25 \mathrm{mM} \text { NaCl-treated } \\
\text { roots (2h) }\end{array}$} & \multicolumn{2}{|c|}{$\begin{array}{c}\begin{array}{c}\text { Non-stressed } \\
\text { nodules vs roots }\end{array}\end{array}$} & \multicolumn{2}{|c|}{$\begin{array}{l}25 \mathrm{mM} \text { NaCl-treated } \\
\text { nodules (2h) }\end{array}$} \\
\hline & & & $\begin{array}{l}\text { Up. } \\
\text { regulated }\end{array}$ & $\begin{array}{c}\text { Down: } \\
\text { regulated } \\
\end{array}$ & $\begin{array}{l}\text { Nodule: } \\
\text { prevalent }\end{array}$ & $\begin{array}{c}\text { Root- } \\
\text { prevalent }\end{array}$ & $\begin{array}{c}\text { Up. } \\
\text { regulated } \\
\end{array}$ & $\begin{array}{l}\text { Down } \\
\text { regulated } \\
\end{array}$ \\
\hline & & Total & 337 & 1,962 & 140 & 361 & 95 & 72 \\
\hline \multirow{2}{*}{ 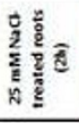 } & Up-regulated & 337 & & & 37 & & 22 & 1 \\
\hline & $\begin{array}{l}\text { Down: } \\
\text { regulated }\end{array}$ & 1,962 & & & & 325 & 1 & 6 \\
\hline \multirow{2}{*}{ 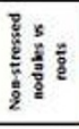 } & $\begin{array}{l}\text { Nodule- } \\
\text { prevalent }\end{array}$ & 140 & 37 & & & & & 14 \\
\hline & $\begin{array}{c}\text { Root- } \\
\text { prevalent }\end{array}$ & 361 & & 325 & & & 3 & \\
\hline \multirow{2}{*}{ 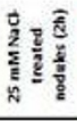 } & Up-regulated & 95 & 22 & 1 & & 3 & & \\
\hline & $\begin{array}{l}\text { Down- } \\
\text { regulated }\end{array}$ & 72 & 1 & 6 & 14 & & & \\
\hline \multirow{3}{*}{\multicolumn{2}{|c|}{ 20.0-fold }} & & \multicolumn{2}{|c|}{$\begin{array}{l}25 \mathrm{mM} \text { NaCl-treated } \\
\text { roots }(2 \mathrm{~h})\end{array}$} & \multicolumn{2}{|c|}{$\begin{array}{c}\text { Non-stressed } \\
\text { nodules vs roots }\end{array}$} & \multicolumn{2}{|c|}{$\begin{array}{l}25 \mathrm{mM} \text { NaCl-treated } \\
\text { nodules (2h) }\end{array}$} \\
\hline & & & $\begin{array}{l}\text { Up. } \\
\text { regulated }\end{array}$ & $\begin{array}{l}\text { Down: } \\
\text { regulated } \\
\end{array}$ & $\begin{array}{c}\text { Nodule: } \\
\text { prevalent }\end{array}$ & $\begin{array}{c}\text { Root- } \\
\text { prevalent }\end{array}$ & $\begin{array}{l}\text { Up. } \\
\text { regulated } \\
\end{array}$ & $\begin{array}{l}\text { Down- } \\
\text { regulated } \\
\end{array}$ \\
\hline & & Total & 31 & 281 & 4 & 36 & 4 & 1 \\
\hline \multirow{2}{*}{ 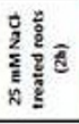 } & Up-regulated & 31 & & & & & 2 & \\
\hline & $\begin{array}{l}\text { Down- } \\
\text { regulated }\end{array}$ & 281 & & & & 32 & & 1 \\
\hline \multirow{2}{*}{$\begin{array}{ll}0 \\
0\end{array}$} & $\begin{array}{l}\text { Nodule- } \\
\text { prevalent }\end{array}$ & 4 & & & & & & \\
\hline & $\begin{array}{l}\text { Root- } \\
\text { prevalent }\end{array}$ & 36 & & 32 & & & & \\
\hline \multirow{2}{*}{ 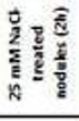 } & Up-regulated & 4 & 2 & & & & & \\
\hline & $\begin{array}{l}\text { Down: } \\
\text { regulated }\end{array}$ & 1 & & 1 & & & & \\
\hline
\end{tabular}

Figure 4 Venn Mapper output detailing shared responses (number of UniTags) between salt-stressed roots and nodules, respectively, and non-stressed nodules relative to roots.

salt stress in both organs, 22 UniTags were commonly more than 8-fold up-regulated. On the other hand, no tags prevalent in non-stressed nodules were more than 8 -fold up-regulated in the same organ upon salt stress (Figure 4, mid panel).
Four 26 bp tags were more than 20-fold differentially expressed between non-stressed nodules and roots. From these, no shared response with any $>20$-fold salt-induced root or nodule transcript was observed (Figure 4, lower panel). Annotatable tags shared by salt-stressed 
Table 3 Overlapping transcriptome responses of UniTags that are highly up-regulated in roots and nodules upon salt stress

\begin{tabular}{|c|c|c|c|c|c|}
\hline Tag ID & Protein & $\begin{array}{l}\text { Fold induction } \\
\text { (roots) }\end{array}$ & $\begin{array}{l}\text { Fold induction } \\
\text { (nodules) }\end{array}$ & $\begin{array}{l}\text { Associated } \\
\text { process }\end{array}$ & Uniprot ID \\
\hline STCa-18884 & Early nodulin & 60,95 & 61,44 & Nodulation & NO40_SESRO \\
\hline STCa-22299 & Predicted protein & 20,70 & 13,65 & Unknown & A9TXV0_PHYPA \\
\hline STCa-17434 & Chitinase-related agglutinin & 18,67 & 13,65 & Defense & A1YZD2_ROBPS \\
\hline STCa-24417 & Lipoxygenase & 24,34 & 12,79 & $\begin{array}{l}\text { Lypid } \\
\text { metabolism }\end{array}$ & B7Z177_PEA \\
\hline STCa-5357 & Phosphatidylinositol transfer-like protein III & 8,12 & 11,94 & Unknown & Q94FN1_LOTJA \\
\hline STCa-175 & Transcription elongation factor 1 & 13,79 & 10,24 & Transcription & ELOF1_ARATH \\
\hline STCa-7855 & Abnormal suspensor SUS2 & 9,74 & 10,24 & Unknown & UPI000016331D \\
\hline STCa-705 & MAP kinase protein & 8,12 & 10,24 & $\begin{array}{l}\text { Signal } \\
\text { transduction }\end{array}$ & Q9SMJ7_CICAR \\
\hline STCa-5894 & General substrate transporter & 34,09 & 8,53 & Transport & A2Q5Z1_MEDTR \\
\hline STCa-5877 & Alternative oxidase & 30,85 & 8,53 & $\begin{array}{l}\text { Redox } \\
\text { homeostasis }\end{array}$ & Q84KA1_CROSA \\
\hline STCa-1885 & Mob1-like protein & 19,47 & 8,53 & Cytokinesis & Q2WBN3_MEDFA \\
\hline STCa-170 & Mob1-like protein & 12,17 & 8,53 & Cytokinesis & Q2WBN3_MEDFA \\
\hline STCa-16125 & Cytochrome c oxidase subunit $6 \mathrm{~b}$ & 11,36 & 8,53 & $\begin{array}{l}\text { Redox } \\
\text { homeostasis }\end{array}$ & Q8LD51_ARATH \\
\hline STCa-8434 & Fiber protein Fb2 & 10,55 & 8,53 & Unknown & Q8GT87_GOSBA \\
\hline STCa-18178 & Probable histone H2A.2 & 9,74 & 8,53 & DNA stability & H2A2_MEDTR \\
\hline STCa-15648 & GR395157.1 C.arietinum EST & 22,30 & 23,87 & Uncharacterized & - \\
\hline STCa-19240 & GR916593.1 C.arietinum EST & 10,54 & 10,23 & Uncharacterized & - \\
\hline STCa-11740 & GR408054.1 C.arietinum EST & 10,54 & 11,94 & Uncharacterized & - \\
\hline STCa-15130 & Contig45449 C.arietinum EST & 8,11 & 8,53 & Uncharacterized & - \\
\hline STCa-7445 & Contig739 C.arietinum EST & 17,84 & 10,23 & Uncharacterized & - \\
\hline STCa-1958 & No homologous EST & 14,61 & 13,65 & Un-annotated & - \\
\hline STCa-8135 & No homologous EST & 8,11 & 8.53 & Un-annotated & - \\
\hline
\end{tabular}

Threshold in organ-wise differential expression: $R_{(\mathrm{In})} 2.0$ (8-fold).

Threshold in stress-treatment differential expression: $R_{(\mathrm{In})} 2.0$ (8-fold).

nodules and roots with a minimum threshold of 8 -fold upregulation in response to salt stress are listed in Table 3.

\section{Global transcriptome differences in stressed roots and nodules}

To uncover global differences between the root and nodule transcriptomes, Gene Score Re-sampling analysis (GSR) for over-representation of GO functional categories was carried out for the total annotated UniTags from both organs. The GSR analysis was fed with the expression levels (fold changes) of each UniTag after stress induction. The GO categories (biological process) undergoing the most significant changes in a stress- and organ-manner were then detected.

Additional to standard GO terms, two custom-made categories were introduced to the GSR analysis, following the procedure of Gillis and co-workers [26]. Over-representation within our data set from transcripts involved in the salt overly sensitive pathway (SOS), and ROS-scavenging mechanisms (SODs, ascorbate and glutathione cycles) was in this way confirmed. Genes belonging to both pathways were filtered from already enriched GO terms and were re-entered into the analysis. A closer detail on both aspects will be assessed on the discussion section.

In chickpea roots from control and salt-treated libraries, a total of 6,637 UniTags were associated to Gene Ontology (GO) terms. After GSR analysis of 450 biological processes, a total of 191 terms were overrepresented with $(\mathrm{P}<0.05)$. From them, 52 biological processes were over-represented with very high significance $(\mathrm{P}<5 \mathrm{E}-10)$. A graphical overview of the GSR results for salt stressed chickpea roots, along with the most significant over-represented GO categories and their representation in nodules of the same plants is depicted in Figure 5.

Not surprisingly, signal-related processes like GO terms GO:0023033 (Signalling pathway), GO:0007165 (Signal transduction), and GO:0023060 (Signal transmission) were over represented. Transport categories like GO:0015031 (Protein transport) and GO:0006812 (Cation transport) were also highly significant. Among the metabolism-related processes, lipid metabolism-related categories (GO:0006629, GO:0044255, GO:0008610) interestingly reacted upon salt stress. Concerning protein homeostasis, terms related to 


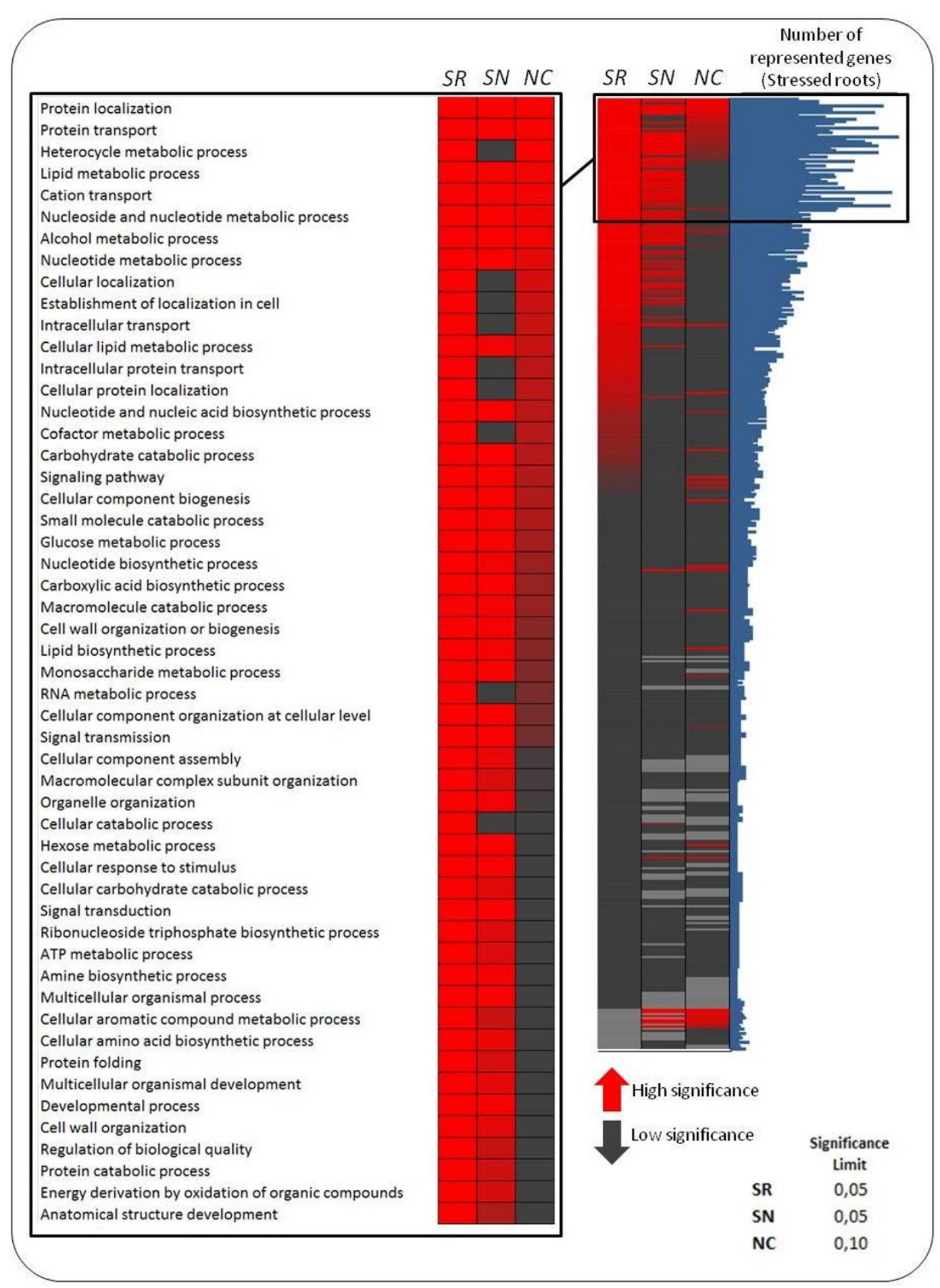

Figure 5 GSR analysis of over-represented GO biological terms in salt-stressed roots and nodules. Right panel: Graphic representation of significant over-represented GO biological processes in stressed roots (SR), stressed nodules (SN), and non-stressed nodules versus non-stressed roots (NC). Numbers of represented genes per GO category in salt stressed roots are represented by the blue bars next to the heat map. Left Panel: Detail showing the 52 most over-represented biological processes for salt stressed roots, compared to stressed and control nodules. 
transport (GO:0015031), folding (GO:0006457), localization (GO:0008104), and catabolism (GO:0030163) also showed P $<1 \mathrm{E}-10$ values.

Diverse response-related terms with different significance levels were also detected. As an example, GO term GO:0051716 (Cellular response to stimulus) was represented by 60 UniProt accessions, showing highly significant over-representation ( $\mathrm{P}<1 \mathrm{E}-10)$, whereas $\mathrm{GO}$ term GO:0033554 (Cellular response to stress) showed a lower significance level $(\mathrm{P}<1 \mathrm{E}-4)$. Globally, from 31 responserelated terms, 9 were over-represented with at least $\mathrm{P}<$ $1 \mathrm{E}-3$. Additionally, quite as expected, SOS- and ROS-custom categories resulted over-represented with $(\mathrm{P}<0.05)$

Nodules of the same INRAT-93 plants differed from roots in their global transcriptome remodelling level after stress induction. From the 450 analysable terms, $102 \mathrm{GO}$ terms were over represented with $(\mathrm{P}<0.05)$. With higher significance levels, 15 and 26 biological processes showed $\mathrm{P}$ values of $(\mathrm{P}<5 \mathrm{E}-10)$ and $(\mathrm{P}<5 \mathrm{E}-4)$, respectively. Ten of the GO terms with very high significance $(\mathrm{P}<5 \mathrm{E}-10)$ were also over-represented in roots of the same plants. Depending on the organ, some sets of different UniProt accessions were associated with each GO term. A clear example is the GO term GO:0006629 (Lipid metabolic process). In roots, 91 UniProt accessions were associated to this term, whereas only 68 were associated in nodules. From them, 6 were not common to both organs (but only associated in nodules). Another example is GO:0009117 (Nucleotide metabolic process), which is represented by 75 and 65 UniProt accessions in roots and nodules, respectively. From them, 16 showed either nodule- or root-specific association.

Concerning processes more induced in stressed nodules while showing no significant representation level in roots, the terms GO:0006508 (Proteolysis), GO:0006811 (Ion transport), GO:0042221 (Response to chemical stimulus), GO:0044106 (Cellular amine metabolic process), and GO:0006022 (Aminoglycan metabolic process) revealed the highest contrasts (Figure 5). On the other hand, 35 terms were more represented in stressed roots, among them, the SOS-custom category). From them, 12 terms showed $(\mathrm{P}<1 \mathrm{E}-10)$ and $(\mathrm{P}>0.5)$ over-representation significances in stressed roots and nodules, respectively (Figure 5). A complete matrix with all analysed processes along with their significance levels of over-representation, and the associated UniProt entries for the different organs and stress conditions are deposited in Additional file 2.

\section{Nodule over-represented GO biological processes under control conditions}

To reveal global transcriptome differences in both organs under control conditions, the differential expression of UniTags from untreated nodules compared to roots was calculated, and the fold changes were fed into
GSR analysis. In non-stressed tissues, the levels of significance for over-representation estimated by the ErmineJ package were substantially lower compared to the ones observed in salt stressed roots and nodules. In control conditions, a total of 15 and 72 GO biological processes were more prevalent in nodules with $(\mathrm{P}<0.05)$ and $(\mathrm{P}<0.1)$, respectively (Additional file 2$)$.

Interestingly, 33 of the $\mathrm{GO}$ biological processes prevalent in nodules $(\mathrm{P}<0.1)$ were over-represented in salt stressed roots at very high significance levels $(\mathrm{P}<1 \mathrm{E}-10)$. Protein machinery- (GO:0008104, GO:0015031, GO:0006886), lipid metabolism- (GO:0006629, GO:0044255), and general metabolism-related (GO:0006066, GO:0051186, GO:0044282, GO:0006006) terms were among these common processes. From 15 GO terms prevalent in nodules with $(\mathrm{P}<0.05), 10$ were over-represented in salt-stressed nodules with the same significance threshold. Among these common processes, highest on the rank of over-representation in control nodules, the ROS custom category showed a significance of $(\mathrm{P}<0.013)$. All common over-represented GO biological processes in untreated nodules and salt-stressed roots are summarized in Table 4.

\section{Information transfer from UniTag profiles to other platforms \\ In situ visualization of two ascorbate peroxidase (APX) transcripts in chickpea nodules}

To test the transferability of information between UniTag profiles and other platforms, selected nodule-metabolism-associated transcripts were localized in chickpea nodules. For this purpose, in situ PCRs of ascorbate peroxidase-annotated UniTags were performed in nodule slices. Main features of the anatomy of chickpea nodules are depicted in Figure 6.

Transcripts from the ascorbate peroxydase 1 (APX1) gene were detected mostly in the inner cortex and less in the outer cortex of control nodules (non-exposed to salinity) (Figure 6). Two hours after exposure to $25 \mathrm{mM}$ $\mathrm{NaCl}$, the transcripts accumulated to high levels in the outer cortex (Figure 7). Note, that the negative controls did not show any fluorescent signal. In contrast, only few transcripts from the APX2 gene appear in control root nodules, whereas the number of transcripts highly increased both in the inner and the outer cortex after exposure to salinity (Figure 7).

Ascorbate peroxidase (APX) is a key enzyme that scavenges potentially harmful $\mathrm{H}_{2} \mathrm{O}_{2}$ and thus prevents oxidative damage especially in $\mathrm{N}_{2}$-fixing legume root nodules. In fact, nodules have a high capacity to generate activated forms of $\mathrm{O}_{2}$ such as $\mathrm{H}_{2} \mathrm{O}_{2}$, because of the relatively high rates of respiration during the early response to moderate salt stress. The elevated levels of transcripts encoding ROS scavengers in the outer and inner cortex, like APX2 in our study, point to a critical role of these regions in ROS- 
Table 4 Commonly over-represented GO biological processes in chickpea salt stressed roots and non-treated nodules

\begin{tabular}{|c|c|c|c|}
\hline GO Biological process & GO Term ID & $\mathrm{P}$ value ( $\mathrm{NaCl}$ Roots) & $P$ value (ctr nodules) \\
\hline Protein transport & GO:0015031 & $8,76 \mathrm{E}-12$ & 0,0235 \\
\hline Protein localization & GO:0008104 & $9,98 \mathrm{E}-12$ & 0,0293 \\
\hline Alcohol metabolic process & GO:0006066 & $2,04 \mathrm{E}-11$ & 0,0391 \\
\hline Nucleoside and nucleotide metabolic process & GO:0055086 & $6,13 \mathrm{E}-11$ & 0,0424 \\
\hline Cation transport & GO:0006812 & $2,15 \mathrm{E}-11$ & 0,0427 \\
\hline Lipid metabolic process & GO:0006629 & $1,07 \mathrm{E}-10$ & 0,0469 \\
\hline Heterocycle metabolic process & GO:0046483 & $2,38 \mathrm{E}-11$ & 0,0587 \\
\hline Nucleotide metabolic process & GO:0009117 & $4,29 \mathrm{E}-11$ & 0,0621 \\
\hline Cellular localization & GO:0051641 & $8,58 \mathrm{E}-12$ & 0,0646 \\
\hline Cellular lipid metabolic process & GO:0044255 & $1,05 \mathrm{E}-11$ & 0,0668 \\
\hline Small molecule catabolic process & GO:0044282 & $1,19 \mathrm{E}-11$ & 0,0698 \\
\hline Establishment of localization in cell & GO:0051649 & $8,41 \mathrm{E}-12$ & 0,0710 \\
\hline Intracellular transport & GO:0046907 & $1,13 \mathrm{E}-11$ & 0,0712 \\
\hline Cellular component biogenesis & GO:0044085 & $8,58 \mathrm{E}-11$ & 0,0715 \\
\hline Nucleotide and nucleic acid biosynthetic process & GO:0034654 & $1,79 \mathrm{E}-11$ & 0,0726 \\
\hline Cellular protein localization & GO:0034613 & $1,26 \mathrm{E}-11$ & 0,0736 \\
\hline Cofactor metabolic process & GO:0051186 & $7,15 \mathrm{E}-11$ & 0,0739 \\
\hline Carbohydrate catabolic process & GO:0016052 & $1,23 \mathrm{E}-11$ & 0,0740 \\
\hline Signaling pathway & GO:0023033 & $1,95 \mathrm{E}-11$ & 0,0751 \\
\hline Glucose metabolic process & GO:0006006 & $1,16 \mathrm{E}-11$ & 0,0755 \\
\hline Intracellular protein transport & GO:0006886 & $1,65 \mathrm{E}-11$ & 0,0758 \\
\hline Nucleotide biosynthetic process & GO:0009165 & $1,38 \mathrm{E}-11$ & 0,0766 \\
\hline Macromolecule catabolic process & GO:0009057 & $1,87 \mathrm{E}-11$ & 0,0766 \\
\hline Carboxylic acid biosynthetic process & GO:0046394 & $1,72 \mathrm{E}-11$ & 0,0774 \\
\hline RNA metabolic process & GO:0016070 & $1,48 \mathrm{E}-11$ & 0,0829 \\
\hline Monosaccharide metabolic process & GO:0005996 & $2,26 \mathrm{E}-11$ & 0,0831 \\
\hline Cellular component organization at cellular level & GO:0071842 & $8,94 \mathrm{E}-12$ & 0,0842 \\
\hline Cell wall organization or biogenesis & GO:0071554 & $9,53 \mathrm{E}-12$ & 0,0842 \\
\hline Lipid biosynthetic process & GO:0008610 & $3,58 \mathrm{E}-11$ & 0,0859 \\
\hline Signal transmission & GO:0023060 & $3,06 \mathrm{E}-11$ & 0,0860 \\
\hline Organelle organization & GO:0006996 & $1,59 \mathrm{E}-11$ & 0,0958 \\
\hline Macromolecular complex subunit organization & GO:0043933 & $1,07 \mathrm{E}-11$ & 0,0972 \\
\hline Cellular component assembly & GO:0022607 & $1,34 \mathrm{E}-11$ & 0,0986 \\
\hline ROS-scavengers & Custom & 0,0088 & 0,0131 \\
\hline
\end{tabular}

scavenging, thereby counteracting by-products of respiration caused by leakage of the electron transport chain. Therefore, elevated levels of APX would be required to provide adequate antioxidant defence. Although nodules possess an array of antioxidant metabolites and enzymes that prevent the generation of highly oxidizing radicals (as e.g. $\left.\mathrm{O}^{2-}, \mathrm{OH}^{-}\right)$and hence the damage of lipids, proteins, and DNA, to name some. In addition, antioxidants regulate the intracellular concentrations of reactive oxygen species, such as the superoxide radical and hydrogen peroxide $\left(\mathrm{H}_{2} \mathrm{O}_{2}\right)$, that are signalling stress perception and activating stress-responsive genes [27,28].

Quantification of oxylipin-related UniTags via qPCR

The GSR analysis in salt-stressed chickpea roots and nodules revealed lipid-metabolism associated categories among the stress over-represented GO biological processes (GO:0006629, GO:0044255, GO:0008610). Lipoxygenases and other oxylipin-related UniProt accessions belong to genes (proteins) most frequently associated with the respective GO terms (http://www.ebi.ac. uk/QuickGO/GTerm?id=GO:0006629).

Oxidized fatty acids, known as oxylipins, are compounds tightly linked to ROS metabolism and stress responses in plants [29]. These compounds, which are generated by the coordinated action of lipases, lipoxygenases, and some cytochrome P450 enzymes, are key elements of jasmonic acid (JA) biosynthesis. JA represents a signalling molecule, that, apart from stress responses, is also involved in developmental processes [30]. A set of oxylipin-related transcripts was selected and confirmed by qRT-PCR, and their expression levels were compared in different chickpea varieties. Among more than 20,000 surveyed transcripts, 


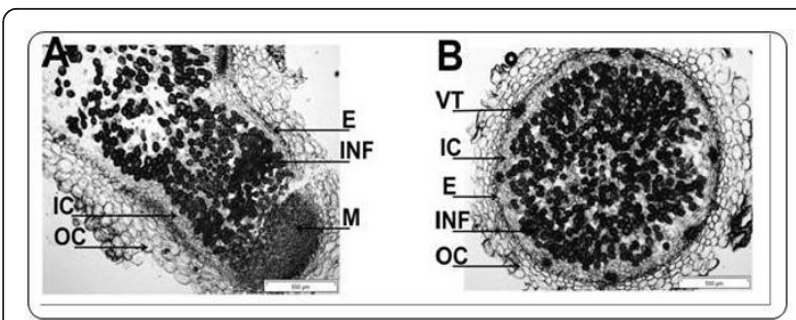

Figure 6 Longitudinal (A) and cross section (B) through a chickpea nodule. Abbreviations: (INF) Infected zone, (NP) Nodule parenchyma, (E) Endodermis, (NC) Nodule cortex, (VT) Vascular trace, (IC) Inner cortex, (OC) Outer cortex, (M) Meristem.

20 UniTags annotated to lipoxygenases were distributed over 11 SAATs families and annotated to 9 different UniProt accessions. These UniTags varied their expression levels from 5fold down-(STCa-20253) to 25fold up-regulation (STCa-24417) $2 \mathrm{~h}$ after onset of salt stress in chickpea roots.

Allene oxide cyclase (AOS) is an enzyme involved in JA biosynthesis by catalysing the conversion of fatty acid hydroxyperoxides to 12-oxophytodienoic acid (OPDA) [31]. In chickpea roots and nodules, five UniTags could be annotated to two AOS UniProt accessions. Expression levels for the respective UniTags varied from 4-fold up-regulation to 20 -fold down regulation.

Comparative qRT-PCR assays using RNAs from chickpea varieties INRAT-93 (salt-tolerant), Amdoun1 (saltsensitive), ICC-4958 (sensitive), and ICC-6098 (weakly tolerant) confirmed the deepSuperSAGE data of selected UniTags $2 \mathrm{~h}$ after salt stress in INRAT-93. Additionally, marked differences in expression levels were detected as

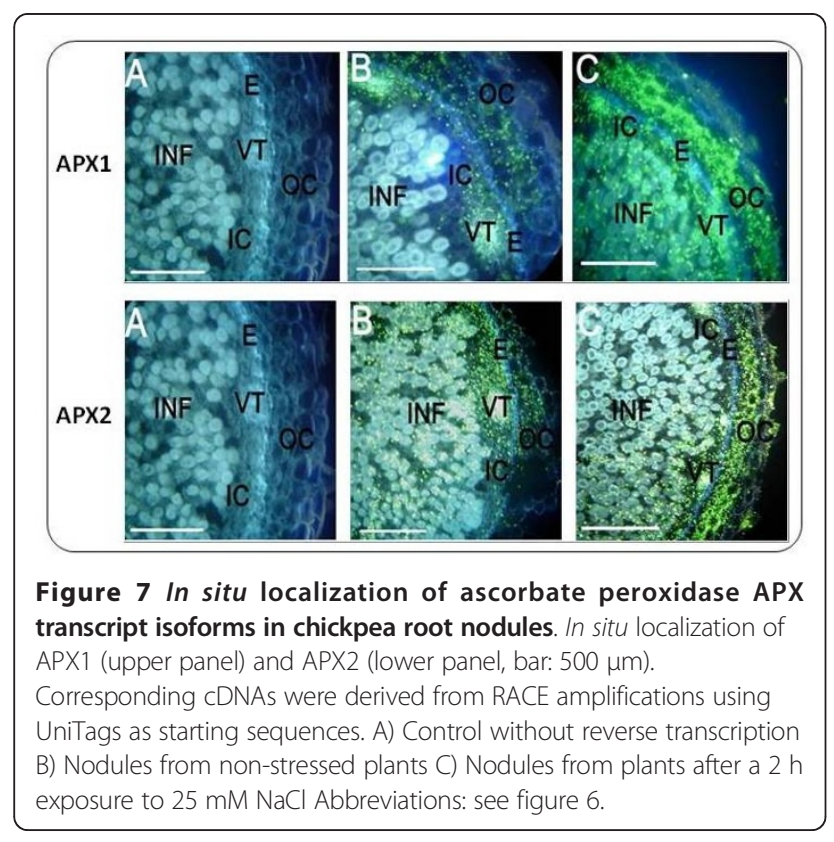

compared to other varieties with lower salt tolerance. A good example is the AOS-annotated transcript STCa13267 (1,6-fold down-regulated in INRAT-93). After comparing the expression of the same AOS transcript via qRT-PCR (using STCa-13267 as starting sequence) in INRAT-93, ICC-4958, and ICC-6098, much higher expression levels were detected in INRAT-93 (especially $2 \mathrm{~h}$ after stress onset, figure 8).

Concerning up-regulated transcripts of the salttolerant variety INRAT-93, cases in which the level of up-regulation was still higher in a salt-sensitive variety were also observed. As an example, the lipoxygenaseannotated 26 bp tag STCa-7252, which is 2,5-fold up-regulated under salt stress in INRAT-93, is much stronger up-regulated in salt-sensitive Amdoun1. This suggests that some of the stress-related genes "overreact" in salt-sensitive plants, which may account for the differences between salt-tolerant and -sensitive varieties (Figure 9). SuperSAGE and qRT-PCR expression profiles of the selected genes in the tested varieties are deposited in Additional file 1.

\section{Confirmation of SuperSAGE expression profiles by microarray hybridization}

SuperSAGE libraries were developed from chickpea plants exposed to other abiotic stresses such as cold (data not shown) and drought stress [32]. From these, a selection of approximately 3,000 26 bp tags with diverse regulation levels were spotted onto an Agilent ${ }^{\mathrm{TM}} 16 \mathrm{~K}$ micro-array

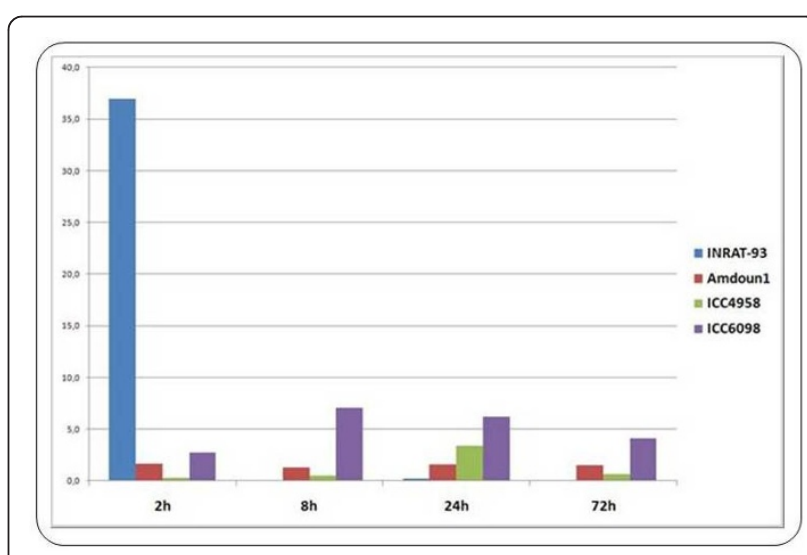

Figure 8 Relative expression levels of AOS-annotated transcripts in four chickpea varieties at different time points after salt stress onset, measured by qRT-PCR. The expression level of the INRA-93 derived 26 bp tag STCa-13267, annotated to an allene oxide synthase (AOS), was determined in the salt-tolerant chickpea variety (INRAT-93) and compared to less tolerant varieties. According to deepSuperSAGE, the AOS-annotated transcript is slightly (1,6-fold) down-regulated $2 \mathrm{~h}$ after stress, but the relative expression level remains very high when compared to the one of the salt-sensitive varieties. At subsequent time points, the AOSexpression decreases drastically in INRAT-93, whereas the levels in the salt-sensitive varieties remain constant. 


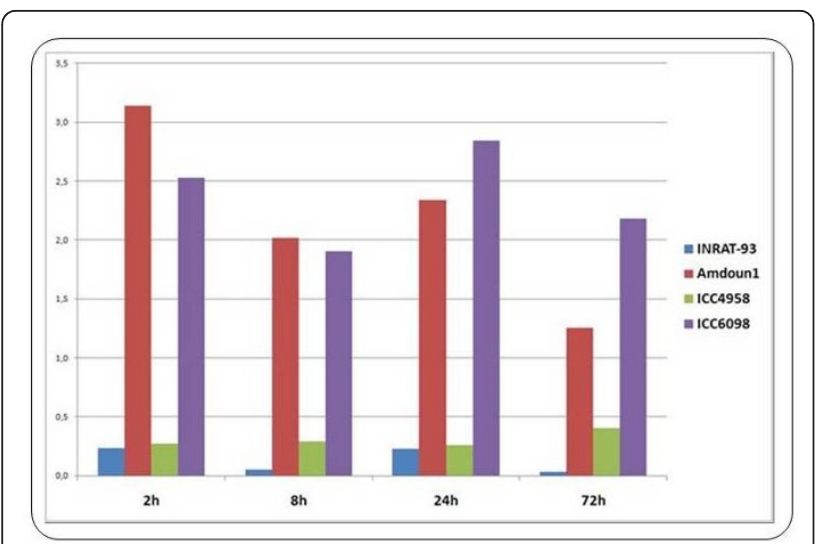

Figure 9 Relative expression levels of a lipoxygenaseannotated transcript in four chickpea varieties at different time points after salt stress onset, measured by qRT-PCR. Transcript levels of chickpea 26 bp tag STCa-7252, annotated to a lipoxygenase gene, remained constant $2 \mathrm{~h}$ hours after salt stress onset in INRAT-93 according to deepSuperSAGE. When compared to the transcript levels of other chickpea varieties, strong differences are observed. The two less salt-tolerant varieties Amdoun1 and ICC6098 show a much higher expression level over time.

(AGILENT TECHNOLOGIES, Santa Clara CA, USA) as 26 bp oligonucleotides (1,200 spotted in duplicate). For each spotted $26 \mathrm{bp}$ tag, similar oligos carrying mismatches were additionally spotted onto the array in three sets as follows: i) mismatch at position 7; ii) mismatches at positions 7 and 13, respectively; and iii) mismatches at positions 7, 13, and 20, respectively. Microarray design followed a previous report [33]. After background correction using the intensities of the oligos carrying mismatches, dye swapping, and statistical treatment, the expression ratios $\left[R_{(\mathrm{ln})}\right]$ from a selection of 66026 bp oligos were compared with the original deepSuperSAGE profiles. Although any comparison of such different profiling platforms is hampered by the differences in signal magnitudes, the almost unavoidable cross-hybridization signals on micro-arrays, the sequence similarity between some spotted 26 bp tags with contrasting regulation levels, and the relatively short size of the spotted oligos (26 bp), a shared tendency towards up- or down-regulation of transcripts of $79.0 \%$ was observed between both platforms (See Additional file 1).

\section{Discussion}

Transcripts abundance and occurrence of SNPs-associated alternative tags

The tag copy numbers within the present chickpea deepSuperSAGE libraries reveal that a substantial proportion of the sampled transcripts is present at low abundance (at least $80 \%$ are found at 1 to 10 copies $\times 100,000^{-1}$ ). This observation is not at all new for plants. In SAGEbased transcriptome analyses in Arabidopsis and maize, at least $70 \%$ of the detected transcripts (excluding singletons) were of low abundance [34,35]. In several other organisms outside the plant kingdom (i.e. yeast, mouse, and humans), large differences between abundant and rare transcripts have also been observed [36].

It is not clear why this proportion of low copy number transcripts is so big in many transcriptomes. It has been suggested that transcripts found in high abundance represent a limited number of house-keeping genes, whereas "rare" transcripts are derived from genes with more specialized functions [37]. In other cases, transcripts encoding proteins with the same function can also display very different ranges of copy numbers [38].

Chickpea root and nodule low copy number UniTags belong to diverse functional categories comprising signalling-, general metabolism-, transcription regulation-, and protein machinery-related biological processes (Additional file 1). Moreover, we observed that some low copy number UniTags accompany high copy number SAATs. Future studies can profit from the information generated in the present work, where more than 13,000 chickpea low copy number transcripts variants are potential candidates for further validation.

Concerning sequence similarity, more than 20,000 UniTags derived from chickpea roots and nodules were analyzed, permitting to follow the expression dynamics of equivalent 20,000 hypothetical complete transcripts. However, how redundant is the original mRNA population, and what level of variation is observed between transcripts, still remain questions to further explore. We have observed that around $70 \%$ of the transcripts contained in a certain chickpea library are different to each other, whereas the remaining 30\% can form families of very similar 26 bp tags, many of them with contrasting expression profiles. Up to date, no extensive study of this phenomenon in plants exists, that could be exploited for the explanation of the observed results. However, in humans, as exemplarily reported for cancer cells, tags generated by SAGE-related techniques are very often differentiated from each other only by SNPs [39]. Extensive studies in which the tag-to-transcript assignment has been approached in deep resolution show that SNP-associated alternative tags (here named SAATs) were observed for nearly $8,6 \%$ of all known human genes. Additionally, from all analyzed transcripts, $2.6 \%$ harbored a SNP contiguous to a terminal NlaIII (the SuperSAGE tagging enzyme) recognition site [22].

Considering the appearance of very similar transcripts in an organism, the occurrence of SNPs within ESTs in humans has been associated to the high flexibility of the transcriptome that allows the generation of varying transcript "isoforms" from a single genomic locus, a phenomenon also reported in Arabidopsis [40-42]. In several cases these small sequence differences have 
been associated to changes in RNA stability and/or decay rate, translation rates, cell- and tissue-localization, and stability of the produced protein [43-45].

The present study delivers valuable information from more than 6,000 chickpea transcripts that present small sequence variations, and nevertheless very different expression levels under salt stress conditions. Future studies in which finer tissue- or cell type-resolution is achieved may profit from the present data, and answer several questions, that up to now remain open.

\section{Salt stress-induced differential gene expression in chickpea roots}

After analysis of more than 17,500 26 bp tags from chickpea roots, UniTag STCa-16261 (Q3LF77_PEA, pathogenesis-related leaf protein 1, PR1) represented the most up-regulated transcript in salt-treated chickpea roots with a more than 70fold up-regulation. Proteins of this family have previously been associated to defense responses and plant stress (http://pir.georgetown.edu/ cgi-bin/ipcSF?id=PIRSF002704). Apart from STCa-16261 (present in 184 copies $\times 100,000^{-1}$ ), 9 similar alternative UniTags are annotated to the same EST (all found in low copy numbers). Although it is known that the encoded proteins are most probably involved in extracellular signaling, no targets or activators are known. The present results expand our knowledge of PR1related proteins and delivers already 10 transcript isoforms with different abundance levels.

Further down the list of top up-regulated UniTags, at least three UniProt accessions associated to ROS-scavenging and redox homeostasis are found, represented by UniTags annotated to one superoxide dismutase (Q9ZNQ4_CICAR, SOD), two lipoxyenases (Q43817_PEA, B7Z177_PEA), and one alternative oxidase (Q84KA1_CROSA). Reports on high activity of ROS-related genes under stress are already known from plants, an aspect that has been extensively reviewed elsewhere [46]. However, to extract transcript populations for candidates with pronounced stress responses is a crucial task. As an example, transcript profiles of at least further 27 lipoxygenase-annotated transcripts are reported here (Additional file 1).

Related to genes from other functional categories, Trypsin inhibitors rapidly accumulate in plants under salt, drought, high aluminum stress, wounding, fungal infection, and ABA and jasmonate applications [47]. Particularly in the first stages of salt stress response in rice, various trypsin inhibitor isoforms are very active [48]. Extensin proteins are generally involved in cell-wall modifications to counteract mechanical pressures arising from differences in water potential $[49,50]$. Although dormancy-associated proteins are salt stress-induced in M. truncatula, very little is known about their exact functions [51]. As growth-promoting phytohormones, auxins function in the regulation of root development in salt-stressed plants [52]. Therefore, the over-expression of UniTag STCa-17087 (dormancy-associated protein, O22611_PEA) in salt-treated INRAT-93 roots may be linked to auxin activity and root growth regulation. Reports on the activity of the $\mathrm{NADP}^{+}$-dependent isocitrate dehydrogenase (ICDH) in the facultative halophyte Mesembryanthemum crystallinum already highlighted the importance of this protein under salt stress [53]. However, contrasting the results for chickpea, the activity of ICDH increased in leaves, and decreased in roots in M. crystallinum. Acetyl-CoA synthetase (ACS), a key enzyme in acetate production, does not seem to be involved in the management of osmotic or ionic stress. Only one study is known, in which acetate production levels and the activities of ACS and aldehyde dehydrogenase (ALD) were monitored under hyperosmotic conditions [54]. Also, informations about the role of cysteine synthases in plants under salt stress are rather limited. However, apart from its general role in protein biosynthesis and as a sulfur donor, cysteine is one of the main components of the anti-oxidant glutathione (along with glutamate) [55]. Glutamate and ascorbate are the major redox buffers in plants, representing the ascorbate/glutathione cycle [9].

Any one-by-one listing of all the up- or down-regulated transcripts under certain conditions is not efficient when high-throughput technologies are used, where thousands of genes are monitored in parallel. To date, several approaches overcome the handling of big data masses to extract biological meaning. In the present work, the accumulated large information body has been filtered combining the output of GSR (GO categories over-representation) analysis with literature and metabolic pathways available in public domains. In subsequent sections, a few relevant biological processes will be dissected in some detail.

\section{Up regulated transcripts in salt stressed nodules and common nodule-root responses}

In the present work, the transcription profile of more than 13,000 nodule UniTags has been deciphered. Several functional categories were represented among the most up regulated UniTags, from which a good portion was also up-regulated in salt-stressed roots of the same plants. Several of the underlying genes have been already identified as being stress-responsive in plants, and also in legumes, as is the case with genes encoding alternative oxidases (AOS), lipoxygenases, MAP kinases, cytochrome $C$ oxidases [56-60], transcription elongation factors, and phosphatidylinositol transfer proteins $[61,62]$. All of them representing proteins involved in widely studied signalling and oxidative stress counteraction processes. 
Other highly up-regulated, but less known genes deserve attention as potential candidates for further characterization. Examples are genes encoding agglutinins, proteins whose activity under osmotic stress is only known from few plant studies $[63,64]$. Annotated to proteins of this class, UniTag STCa-17434 (A1YZD2_ROBPS) was 13and 18-fold up-regulated in salt stressed chickpea nodules and roots, respectively. Another case is the high salt tress induction of Mob1-annotated transcripts in chickpea roots and nodules. The involvement of Mob proteins in plant cytokinesis and growth has been studied in detail, yet no connection to stress responses has been reported [65]. In chickpea roots and nodules, Mob1-annotated UniTags STCa-1885 and STCa-170 are at least 8-fold up-regulated in both organs under salt stress, and both UniTags are accompanied by 13 SAATs, many of them showing contrasting expression profiles.

Even less characterized are plant fiber proteins like Fb2, from which only few functional data are available up to date (http://www.uniprot.org/uniprot/Q8GT87. html). Contrary to several other highly stress-induced transcripts in chickpea roots and nodules, $\mathrm{Fb} 2$ proteins are represented by only one single UniTag (STCa-8434), without any related SAAT. However, we could annotate further 15 UniTags to at least six other Fb classes.

As described above, the present results encompass sets of transcript variants derived from previously described genes together with their expression profiles and sequences (and derived similarities). Although a compilation of stress-regulated genes is not new, the present information on the dynamics of their transcript variants in chickpea roots and nodules merits attention.

Also, an important objective in high-throughput transcriptomics is the discovery of new genes. Among the highly stress up-regulated (>8-fold) UniTags from chickpea nodules and roots (detailed in Table 3), five UniTags were annotated to ESTs with no homology to any characterized plant mRNA or genic DNA sequences. These ESTs showed no significant BlastX complete hits to proteins deposited in the public domain. The respective UniTag- and complete chickpea target ESTs-sequences from unannotated transcripts are deposited in Additional file 3.

\section{Cross-feedback of GO representation analysis and abiotic stress-related pathways}

Handling the large masses of data derived from highthroughput transcriptome studies implies extensive filtering of information. In the present study, GSR overrepresentation analysis of GO categories provided a view of the global transcriptome of chickpea roots and nodules and its remodelling under stress. However, instead of defining discrete pathways, GO terms group genes or proteins according to their associated biological process, cell components, or molecular functions (http:// www.geneontology.org). So we re-screened the output of our GSR analysis to monitor the dynamics of transcripts associated with pathways represented in certain GO categories. Here, two stress-related processes are discussed in detail, i) the regulation of cellular $\mathrm{Na}^{+}$homeostasis, and ii) counteraction of reactive oxygen species (ROS). Although these two processes are widely studied in plants, a detailed search for potential pathway members, their transcript isoforms and their expression profiles, is still missing in several non-model crops [66].

$\mathrm{Na}^{+}$homeostasis and potential salt overly sensitive (SOS) members in chickpea

In plants, the salt-sensitive-overly (SOS) pathway partly manages the excess of $\mathrm{Na}^{+}$ions under saline stress conditions by the interplay of calcineurin B-like (SOS3/CBL4) $\mathrm{Ca}^{2+}$ sensors with $\mathrm{CBL}$-interacting protein kinases (SOS2/CIPK24), that regulate directly the activity of the SOS1 protein $\left(\mathrm{Na}^{+} / \mathrm{H}^{+}\right.$antiporter $)$, and indirectly, a broad array of proton pumps (mostly $\mathrm{H}^{+}$ATPases) [67-70]. Additionally to SOS1 to 3, SOS4 and SOS5 proteins have been identified to interact with the other SOS members. SOS4 encodes a pyridoxal (PL) kinase, whereas SOS5 encodes a polypeptide partly homologous to proteins of the arabinogalactan class (AGP) [71].

The SOS cascade has been initially studied in detail in Arabidopsis knock-out mutants, and later on also in other plants like rice, poplar, and several brassica species [72-75]. In salt stressed chickpea roots, after a cross-fed screening between the GSR results and SOS pathway members, four highly over-represented $(\mathrm{P}<1 \mathrm{E}-10)$ biological processes revealed to contain potential members of the SOS cascade among their associated gene accessions. GO terms: GO:0009628 (response to abiotic stimulus), GO:0023060 (signal transmission), GO:0006812 (cation transport), and GO:0007165 (signal transduction).

Here we report a set of 13 and 7 chickpea UniTags annotated to at least 9 and 5 CIPKs and CBLs, respectively. These UniTags revealed diverse expression levels in a range between 24-fold down- and 7-fold up-regulation in salt-stressed roots, and 4-fold down- and 6-fold up-regulation in nodules, respectively. To our knowledge, no potential members of this pathway are yet known in both chickpea organs. Additionally, at least 90 UniTags distributed in 61 similar tag families (representing 47 UniProt accessions) were annotated to proton pump ATPases, proteins which can be controlled by the SOS network [67]. Concerning SOS4 and SOS5, only a single UniTag annotated to a pyridoxal kinase was detected (Q4JR83_SOYBN, STCa-4652), whereas 12 UniTags distributed in five SAAT families where annotated to AGPs. A summary of the UniTags representing the distinct CBLs, CIPKs, and AGPs is deposited in Table 5. Complete sequences of the respective 
Table 5 Summary of chickpea CBL- CIPK- and AGP-annotated UniTags in chickpea roots and nodules

\begin{tabular}{|c|c|c|c|c|c|c|}
\hline & UniTag ID & Sequence & Uniprot ID & Gene class & $R_{(I n)}$ Roots & $\mathrm{R}_{(\mathrm{In})}$ Nodules \\
\hline \multirow[t]{4}{*}{ CBL proteins } & STCa-10400 & CATGCTTGTTATAGTTAGCCTTTCTC & Q5EE13_9FABA & CBL & $-0,21$ & $-0,16$ \\
\hline & STCa-8869 & CATGCCTTACTTTGGGTGTGACGATT & Q7FZ95_EUCGR & $\mathrm{CBL}$ & 0,89 & $-0,16$ \\
\hline & STCa-12426 & CATGGATGTGGAAAATGAAATCCTTG & CNBLA_ARATH & CBL 10 & $-0,90$ & 0,53 \\
\hline & STCa-7792 & CATGCATATGTACTGAACCCAGTTAA & A4ZKI5_POPTR & CBL 4-1 & $-2,00$ & $-0,16$ \\
\hline \multirow[t]{10}{*}{ CIPK proteins } & STCa-4035 & CATGAGTTTGAGATTTGTACTGTTGT & Q8LK24_SOYBN & CIPK & 0,20 & $-0,16$ \\
\hline & STCa-1179 & CATGAAGAATCCTTGTTGATGATTCA & Q8LK24_SOYBN & CIPK & 1,99 & $-0,38$ \\
\hline & STCa-21948 & CATGTGTTACTTGGGAGTGTCTGGTT & AOMNJ9_POPTR & CIPK 12 & 1,58 & 1,63 \\
\hline & STCa-19413 & CATGTCAAACTACAGCAGCTGAAGCT & AOMNK6_POPTR & CIPK 19 & $-1,60$ & $-0,85$ \\
\hline & STCa-19111 & CATGTATGTATGGATATATATATACT & AOMNK8_POPTR & CIPK 22 & 0,89 & 0,53 \\
\hline & STCa-5485 & CATGATGTTATTATTTTTGATTTGAT & AOMNL1_POPTR & CIPK 25 & $-0,21$ & 0,53 \\
\hline & STCa-21387 & CATGTGGTGTTATTCTCTTTGTTCTT & AOMNL1_POPTR & CIPK 25 & 0,48 & $-1,55$ \\
\hline & STCa-12635 & CATGGCAAGGAGAACAACCACAGCAA & AOMNL4_POPTR & CIPK 6 & $-2,80$ & $-0,72$ \\
\hline & STCa-132 & CATGAAAAGAATAGTGGGTAGTGTTT & CIPK7_ARATH & CIPK 7 & $-0,21$ & $-0,85$ \\
\hline & STCa-6698 & CATGCAATGTAATATAAGACCCTAAT & CIPK9_ARATH & CIPK 9 & $-1,19$ & 1,92 \\
\hline \multirow[t]{12}{*}{ AGP proteins } & STCa-17547 & CATGTAATGTAATATTGTTGAATGAA & Q8L5F8_CICAR & AGP & - & 0,53 \\
\hline & STCa-18898 & САTGTATCATTTATTTTCTTTTTTTG & Q9XIV1_CUCSA & AGP & 1,40 & 0,53 \\
\hline & STCa-17548 & CATGTAATGTAATATTGTTGTGAAAA & Q8L5F8_CICAR & AGP & 0,89 & - \\
\hline & STCa-17550 & CATGTAATGTAATATTGTTGTGATTT & Q8L5F8_CICAR & AGP & $-0,12$ & 0,28 \\
\hline & STCa-23251 & CATGTTGATGTTGGAGAGAGGGCTTT & AGP20_ARATH & AGP & 0,53 & 0,22 \\
\hline & STCa-17544 & CATGTAATGTAATATCGTTGTGATTT & Q8L5F8_CICAR & AGP & 0,48 & - \\
\hline & STCa-17549 & CATGTAATGTAATATTGTTGTGATTA & Q8L5F8_CICAR & AGP & 0,48 & - \\
\hline & STCa-19513 & CATGTCACAACTCATAAAAAAGTACA & Q8L5F8_CICAR & AGP & - & $-0,16$ \\
\hline & STCa-21051 & CATGTGGAGTAGTTTGATTTGTGCAG & Q8L5F8_CICAR & AGP & $-0,21$ & - \\
\hline & STCa-635 & CATGAAATGTAATATTGTTGTGATTT & Q8L5F8_CICAR & AGP & - & $-0,85$ \\
\hline & STCa-23101 & CATGTTGAAGTGAAATATGAAATGAA & A7J385_GOSHI & AGP & 0,48 & $-0,85$ \\
\hline & STCa-8606 & САTGCССТСАССТСТССТTTСАТСАТ & AGP25_ARATH & AGP & $-1,60$ & $-1,55$ \\
\hline
\end{tabular}

homologous chickpea ESTs are deposited in Additional file 1. These transcripts may serve as starting point for validation of their function in chickpea.

\section{ROS management in salt stressed chickpea roots and} nodules

The production and management of reactive oxygen species (ROS) are major early events of the stress response in plants, and consequently these features are enriched among over-represented GO terms in chickpea. ROS-scavenging is well-known from several stress contexts in plants, and therefore we will not repeat informations here [76,77]. However, filtering of the present dataset for transcript variants encoding proteins involved in ROS-related processes should identify candidate ESTs for further characterization.

As a response of plants to ROS overproduction arising from stress-induced metabolic imbalance, dismutation of superoxide $\left(\mathrm{O}_{2}{ }^{-}\right)$radicals by SOD occurs very quickly [78]. A total of 17 UniTags annotated to 7 SOD UniProt entries were detected in the INRAT-93 root and nodule dataset. From them, two SAAT families each with four UniTags were detected, whereas the remaining UniTags showed 1, or no associated SAAT. Belonging to one of the fourSAAT families, STCa-7896 was the most differentially expressed SOD UniTag under salt stress (40-fold up regulation in roots).

After dismutation of superoxide to hydrogen peroxide $\left(\mathrm{H}_{2} \mathrm{O}_{2}\right)$, catalases (CATs), ascorbate peroxidases (APXs), dehydroascorbate reductases (DHARs), glutathione peroxidases (GPXs), glutathione reductases (GRs), and glutathione-S-transferases (GSTs) finish the $\mathrm{H}_{2} \mathrm{O}_{2}$ scavenging process via the ascorbate and glutathione cycles $[8,9,27]$. In salt stressed chickpea roots and nodules, diverse expression profiles were revealed by UniTags annotated to these enzymes. Several of these transcripts are very active in nodules even before the onset of the stress, probably due to the high metabolic activity of these chickpea organs [79]. A total of 59 UniTags annotated to proteins belonging to the ascorbate and glutathione cycles were detected in the present dataset. An overview of the plant genes involved in basic ROS-scavenging mechanisms along with the UniTag transcript levels in salt-stressed roots and nodules is depicted in Figure 10. Fold-regulation, annotation to anonymous chickpea ESTs, sequences, and information on copy numbers per SuperSAGE library for the above detailed pathways are accessible through the filtering options on Additional file 1. 


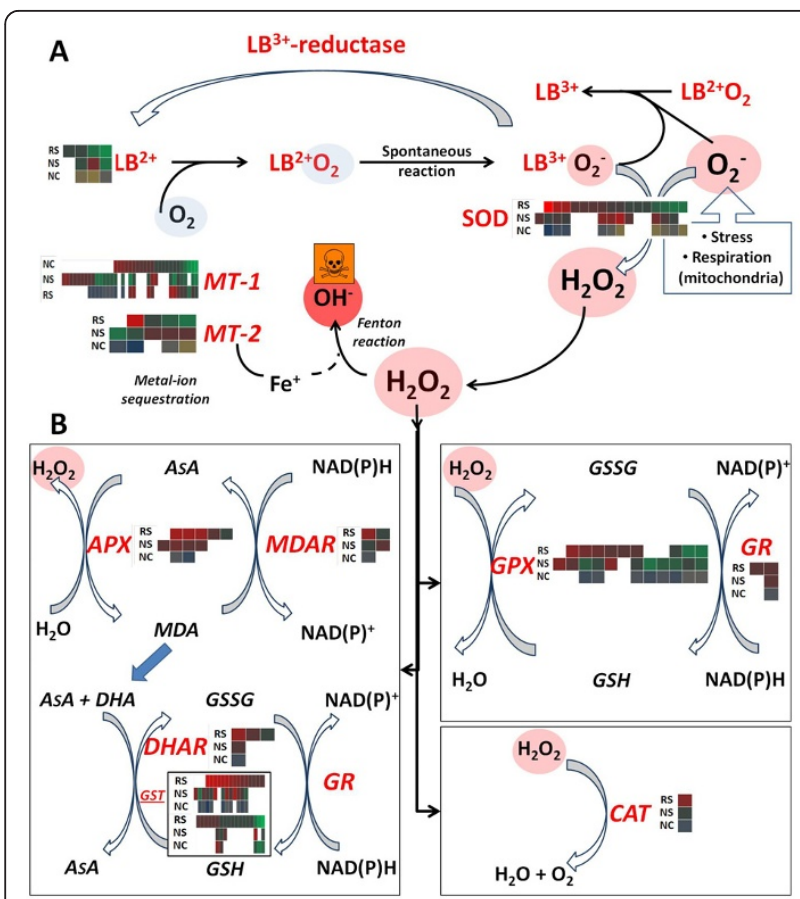

Figure 10 Expression profiles of genes encoding proteins producing or detoxifying reactive oxygen species (ROS) in chickpea roots and nodules. A) In the very intricate ROS pathway in legume nodules, superoxide radicals $\left(\mathrm{O}_{2}{ }^{-}\right)$are generated by elevated mitochondrial respiration rates. In turn, leghemoglobin $\left(\mathrm{LB}^{2+}\right)$, the enzyme keeping the nodules free of molecular oxygen $\left(\mathrm{O}_{2}\right)$, can spontaneously be converted to ferric $L B\left(\mathrm{LB}^{3+}\right)$, generating new $\mathrm{O}_{2}$. These radicals can induce further conversions of $\mathrm{LB}^{2+}$ to $\mathrm{LB}^{3+}$. The generated superoxide radical can be directly dismutated by $\mathrm{SOD}$ to $\mathrm{H}_{2} \mathrm{O}_{2}$, which is immediately decomposed, as depicted in (B). On the other hand, $\mathrm{H}_{2} \mathrm{O}_{2}$ can generate hydroxyl radicals $\left(\mathrm{OH}^{-}\right)$in the presence of abundant free $\mathrm{Fe}^{+}$ions, which are sequestered by metallothioneinlike proteins. B) Hydrogen peroxide can be scavenged via the glutathione/ascorbate cycles or the action of catalases (CAT) NC: UniTag expression profiles indicating prevalence in nodules (with various intensities of blue):Organ-specific expression NS and RS UniTag expression profiles of roots and nodules, and up- and downregulation under salt stress (with various intensities of red and green, respectively): Stress-specific expression

\section{Up-regulation of stress-related transcripts in non-treated chickpea nodules}

One of the most interesting features observed on the present chickpea SuperSAGE profiles relies on the fact that several UniTags found to be prevalent in untreated nodules, become highly induced in roots after salt stress. Here, 515 and 37 UniTags resulted nodule-prevalent and salt up-regulated in roots with 3- and 8-Fold differential expression thresholds, respectively. Results that were corroborated by the GSR analysis, where at least $33 \mathrm{GO}$ biological processes prevalent in untreated nodules are also over-represented in stressed roots (results previously summarized in Table 4).

To spot an example, the high representation of genes related to ROS-scavenging in non-stressed chickpea nodules, like SODs, can be explained by the metabolic demands from the nitrogen fixing machinery, whereas in salt stressed roots the high SODs induction could be triggered by a general ionic disequilibrium $[28,80]$. Whether this type of early induction presents any help for the plant to overcome any oncoming stress is an interesting question, not only for ROS-scavengers, but for several other categories showing similar tendencies in chickpea roots and nodules.

Previous works on poplar plants colonized by Ectomycorrhizas (EM) have already suggested that the symbiotic partnership acts as stress pre-priming event, conferring better salt stress performance to EM-colonized plants. Through a combined transcriptome and metabolome approach, Luo and co workers identified a series of common up regulated genes between EM-colonized and salt stressed poplar roots [81]. In a parallel work on droughtstressed poplar, Beniwal and co-workers found similar results [82]. On both cases, the better stress performance of EM-colonized plants involved genes acting on signaland stress related-pathways as well as genes involved in growth and tissue structural modifications.

Despite large differences in the type of symbiotic association, plant families, and experimental conditions, a set of 6 genes sharing the same tendencies in chickpea and poplar was filtered out. Main features are deposited in Table 6. This set of genes involves ROS-, general metabolism-, nitrogen compounds transport-, and cell structure-related biological processes. The represented transcripts can be taken as candidates for further characterisation. The present work delivers already information about their expression profiles, transcript isoforms, and homologous high quality ESTs sequences.

\section{Information transfer from SuperSAGE to other platforms}

Previous reports already capitalized on the transfer of sequence information from SuperSAGE to microarrays platforms [33]. In the present study, 26 bp oligos with UniTag sequences were directly spotted onto Agilent ${ }^{\circledR}$ $16 \mathrm{~K}$ arrays. In general, the signal background levels were relatively high, leading to loss of information. Nevertheless, after comparing the results from the $16 \mathrm{~K}$ Agilent arrays with SuperSAGE profiles, a high proportion of transcripts (79\%) showed shared regulation tendencies (Additional file 1). However, the signal intensities on the array did not correlate completely with the SuperSAGE expression ratios. Therefore, microarray and SuperSAGE results were confirming each other (up- or down-regulation), but were not congruent in the degree of differential expression.

One of the major drawbacks for the transfer of information from SAGE-based techniques to cDNA chips is the loss of resolution. Whereas very similar transcripts could be differentiated in silico by SuperSAGE, this degree of 
Table 6 Nodule prevalent genes that were stress up-regulated chickpea roots and were equally detected in poplar roots after stress induction or EM-colonization

\begin{tabular}{|c|c|c|c|c|c|c|c|}
\hline \multirow[b]{2}{*}{ ID } & \multirow[b]{2}{*}{ Uniprot ID } & \multirow[b]{2}{*}{ EST ID } & \multirow[b]{2}{*}{ Prot Name } & \multicolumn{2}{|c|}{ Fold change } & \multirow[b]{2}{*}{ Biological Process } & \multirow[b]{2}{*}{ N. of SAATS } \\
\hline & & & & Sress roots & Ctr Nodules & & \\
\hline STCa-10397 & G3PC_PEA & GR406687.1 & G3PDH & 5,68 & 7,63 & Carbohydrate metabolism & 3 \\
\hline STCa-1533 & Q7XHJ2_QUERO & FE672553.1 & Expansin-like protein & 14,61 & 9,54 & Cell. structure/Reproduction & 0 \\
\hline STCa-22470 & Q948X4_MEDSA & Contig 19047 & Glutathione S-transferase & 12,17 & 19,09 & ROS scavenging & 0 \\
\hline STCa-15256 & Q9FQE1_SOYBN & Contig43760 & Glutathione S-transferase & 8,12 & 7,63 & ROS scavenging & 4 \\
\hline STCa-24366 & Q8L5Q7_CICAR & Contig43760 & Quinone oxidoreductase & 8,12 & 11,45 & Transcription/Oxidation-reduct. & 3 \\
\hline STCa-16259 & Q9FSH3_LOTJA & Contig9994 & Ammonium transporter & 7,30 & 5,73 & Transport & 0 \\
\hline
\end{tabular}

differentiation can present problems for hybridizationbased techniques [83]. At present, diverse technologies have already been applied for the detection of SNPs on microarrays. However, these approaches are more directed towards genotyping than to expression profiling [84-86]. Additionally, low-abundant transcripts represent another big obstacle in the use of SuperSAGE-based microarrays. As reported for human neuronal tissue with a transcriptome full of low-abundant mRNAs, the power of microarrays is limited when "rare" messages are evaluated [87]. In the present study, most of the spotted 26 bp tags were selected on the basis of their up- or down-regulation, implying that their copy numbers are relatively high. Therefore, the microarray-based profiles do not monitor tags of low abundance. Despite the relatively good tendency congruence in both techniques for the analyzed transcripts, these drawbacks emphasize, that better strategies are still needed to improve the transference of information from deepSuperSAGE expression profiling to hybridization-based platforms.

Parallel to microarray spotting, the sequence information from the $26 \mathrm{bp}$ tags was used as starting point to generate $\mathrm{qPCR}$ and in situ PCR amplifiable fragments via 3'- and 5'-RACE (data not shown). In few cases, RACE amplifications using the UniTag as starting sequence produced more than one product, which in many of the cases reflect the same homology with EST accessions shown by the original UniTags. RACE amplification of alternative, but similar ESTs is a quite common phenomenon, that could be responsible for the appearance of SNP-associated alternative tags (SAATs) in large SAGE databases [88]. Despite these technical difficulties, we transferred deepSuperSAGE-derived information to qPCR and in situ PCR with satisfactory results. However, hundreds or thousands of assays would be needed for a real estimation of the transfer efficiency.

\section{Conclusions}

In the present study, deepSuperSAGE allowed to profile the transcription of genes coding for proteins involved in ROS scavenging and control of high $\mathrm{Na}^{+}$levels, among many other relevant biological processes, in various situations (roots and nodules under normal and salt stress conditions). The major insights into the prime steps of salt stress response observed in chickpea are: 1) part of the chickpea transcriptome is highly expressed in nodules already under control conditions, and a portion of it becomes highly up regulated in roots only after stress induction. 2) ROS-scavengers are highly represented among transcripts displaying this regulation tendency. This rapid activation of genes in response to salt stress was yet unknown in nodulating legumes. However, the stress-priming effect induced by symbiotic nitrogen-fixing organisms is already known from other systems, as reported for ectomycorrhizal colonization in poplar plants under saline stress [81].

For the first time at all, the magnitude of the organand stress-specific transcriptomes was assessed in chickpea roots and nodules. For more than 21,000 unique transcripts recovered from both organs, a clear organprevalence could be detected, and a stress-response level starting from 3.0-fold and going up to 20-fold differential expression was revealed.

The present report witnesses the potential of the highthroughput deepSuperSAGE technology coupled to one of the next-generation sequencing platforms (here: Roche 454 Life/APG GS FLX Titanium) for a genomewide quantitative gene expression profiling of plants or plant organs under stress.

\section{Methods}

\section{Plant treatments}

Plant treatments and hydroaeroponics conditions were set according to the chickpea work of L'Taief and co-authors in which a salt concentration of $25 \mathrm{Mm}$ $\mathrm{NaCl}$ was chosen to guarantee the functionality of the root nodules [89]. Briefly summarized, surface-sterilized seeds of chickpea cultivars INRAT-93 and Amdoun (sensitive control variety), respectively, were germinated on $0.9 \%$ agar for 5 days in dark chamber at room temperature. Seedlings with a minimum root length of $5 \mathrm{~cm}$ were inoculated with Mesorhizobium ciceri (strain UPMCa7) by dipping each seedling into growing media 
for 10 seconds, and packages of 15 individuals were transferred to twelve 40L hydroaeroponics buckets $(6 \times$ Amdoum, $6 \times$ INRAT-93). Both varieties were kept in separate buckets to obtain a higher homogeneity of plant growth at intra-bucket levels. Buckets were placed alternating I-93 and Amdoum positions in a greenhouse portion showing homogeneity in light and temperature. Inter-Bucket effects were previously tested [89].

Seedlings from both varieties were further grown for 20 days in a temperature-controlled glasshouse with a day/ night temperature regime of $28 / 20^{\circ} \mathrm{C}$ and a $16 \mathrm{~h}$ photoperiod with additional light of $400 \mu \mathrm{mol}$ PAR m-2s-1. Micro- and macro-nutrient concentrations in the growth medium were adjusted to $0.7 \mathrm{mM} \mathrm{K}_{2} \mathrm{SO}_{4}, 1 \mathrm{mM}$ $\mathrm{MgSO}_{4} \cdot 7 \mathrm{H}_{2} \mathrm{O}, 1.65 \mathrm{mM} \mathrm{CaCl}_{2}, 22.5 \mathrm{mM} \mathrm{H}_{2} \mathrm{PO}_{4}$ (macronutrients), and $6.6 \mathrm{mM} \mathrm{Mn}^{2+}, 4 \mathrm{mM} \mathrm{Bo}^{3+}, 1.5 \mathrm{mM} \mathrm{Cu}^{2+}$, $1.5 \mathrm{mM} \mathrm{Zn}^{2+}$ (micronutrients) and additionally $2.0 \mathrm{~g} \mathrm{~L}^{-1}$ $\mathrm{CaCO}_{3}$ as $\mathrm{pH}$ regulator. After one round of compression and filtering, a constant air flow of $400 \mathrm{~mL}$ (compressed air)/liter of solution/minute was applied to each bucket through "spaghetti" tubes system.

Three weeks-old chickpea plants were transferred to 6 new buckets with freshly prepared medium (see above), containing $25 \mathrm{mM} \mathrm{NaCl}(3 \times \mathrm{I}-93,3 \times$ Amdoum $)$. In parallel, control plants were placed into buckets with new nutrition medium without $\mathrm{NaCl}$ following the same schema $(3 \times \mathrm{I}-93,3 \times$ Amdoum $)$. Control and $25 \mathrm{mM}$ $\mathrm{NaCl}$-treated roots and nodules from three randomly chosen plants extracted from three different buckets were harvested separately, and each frozen in liquid nitrogen 1 and 2 hours, respectively, after onset of the stress. Not harvested plants served to monitor changes in fresh and dry weight of INRAT-93 plants (roots, shoots, and nodules) 4 days and 5 weeks, respectively, after stress induction.

\section{SuperSAGE libraries}

Total RNA was isolated from control and stressed roots as described by [75], except that the RNA was precipitated in $3 \mathrm{M} \mathrm{LiCl}$ at $4^{\circ} \mathrm{C}$ overnight. The poly $(\mathrm{A})^{+}$- RNA from about $1 \mathrm{mg}$ total RNA was purified with the Oligotex mRNA Mini Kit (QIAGEN, Hilden, Germany) according to the manufacturer's batch protocol. Subsequent steps for construction of SuperSAGE libraries were detailed in [76]. Amplified ditags were directly sequenced on a Roche 454 Life/APG GS FLX Titanium platform.

\section{Data analysis}

Tags of $26 \mathrm{bp}$ were extracted from the sequences with the GXP-Tag sorter software (GenXPro GmbH, Frankfurt am Main, Germany, http://www.genxpro.de). Library comparisons and primary statistical treatments used DiscoverySpace 4.01 software (http://www.bcgsc.ca/ discoveryspace). Scatter plots of the expression ratios
$\left(\mathrm{R}_{[\mathrm{In}]}\right)$ and and respective P-values were calculated automatically by the DiscoverySpace package following the algorithm of significance for digital expression profiles from Audic and Claverie [11]. Over-representation P values for Gene Ontology (GO) categories (biological processes) observed in the different stress situations were calculated and correlated with the UniTag expression ratios $(\mathrm{R}(\mathrm{ln}))$ by applying the Gene Score Re-sampling (GSR) analysis of the ErmineJ 2.0 software package (University of British Columbia, 2006, http://www.bioinformatics.ubc.ca/ermineJ), as recommended by the software developers [90]. Additionally, cross-feedback of GSR results and stress-related pathways were carried out by constructing artificial categories containing all pathway members for the use of the ErmineJ package, as reported in [26].

\section{Homology searches}

Tag sequences were BLASTed [77] against a total of 44,000 chickpea anonymous ESTs using the stand-alone BLAST routine. Low complexity UniTags were filtered out, and high homologous $(\mathrm{E}<1 \mathrm{E}-5)$ UniTag-EST hits were retained. Subsequently, all anonymous chickpea ESTs were re-annotated to different public databases discriminating the hits in a hierarchical, taxonomical manner using the BLASTN algorithm (http://www.ncbi.nlm.nih. gov/BLAST/). First, all ESTs were BLASTed against the non-redundant DNA databases, limiting the output hits with the highest priority level to Cicer arietinum and members of the Fabaceae, by using the routine BLASTc13 (NCBI, http://www.ncbi.org). Subsequently, individual local BLAST searches were carried out in Fabaceae sequences, followed by Arabidopsis, rice and maize homology searches in the TIGR gene indices (http://compbio. dfci.harvard.edu/tgi/plant.html). After each BLAST round, anonymous DNA sequences (e.g. chromosomes, shotgun clones, and ESTs not linked to any characterized protein) were filtered out. Additionally, ESTs assigned to TIGR TCs indicating weak similarity to characterized genes were not selected. The expected number of random matches (e-value) was kept under 1E-50 for individual TIGR databases larger databases (e.g. NCBI nr restricted to Fabaceae hits). Low complexity regions were rejected, whereas gap costs were set to 5-2 (NCBI BLAST standard setting).

\section{Rapid amplification of CDNA ends (3'-RACE)}

To test the versatility of the $26 \mathrm{bp}$ tag-derived oligonucleotides for direct use as 3'-RACE PCR primers, cDNA amplifications were carried out with an initial denaturation step of $94^{\circ} \mathrm{C}$ for $2 \mathrm{~min}$, followed by 30 cycles each of $94^{\circ} \mathrm{C}$ for $40 \mathrm{sec}, 55^{\circ} \mathrm{C}$ for $1 \mathrm{~min}$, and $72^{\circ} \mathrm{C}$ for $1 \mathrm{~min}$, with a final extension step at $72^{\circ} \mathrm{C}$ for $4 \mathrm{~min}$. Reactions contained 15-20 ng cDNA template, 10 pmol 26 bp tagbased primer, 10 pmol oligodT (t)14-NV primer, 
$200 \mu \mathrm{M}$ dNTPs, 0.4 U Taq DNA polymerase (Genecraft, Germany) in a buffer containing $1.5 \mathrm{mM} \mathrm{MgCl}_{2}$ supplied by the provider. After amplification, products were separated in $1.5 \%$ preparative agarose gels. Bands corresponding to unequivocal amplicons were excised, and DNA extracted with Qiaquick cleanup columns (QIAGEN, Hilden, Germany). Cloning of PCR products as well as colony PCR screening followed standard bluewhite screening procedures [91]. Positive clones were sequenced via ABIprism multi-colour fluorescencebased DNA analysis system (APPLIED BIOSYSTEMS, Foster City CA, USA).

\section{Confirmation of SuperSAGE results by qRT-PCR}

In the course of downstream applications of SuperSAGE/ ST-DGE the mRNA levels of selected genes of salt stressed roots and nodules from four important cultivars of Cicer arietinum: INRAT93-1 (Beja), Amdoun-1, ICC4958 and ICC6098 were measured with qPCR assays. Total RNA was extracted following the protocol of Promega (SV Total RNA Isolation System Kit - manual TM048, http://www.promega. com/tbs/tm048/tm048.html). We elongated the DNaseI digest from original 15 minutes to 30 minutes on the column. Total RNA concentration was estimated in dilution series with LabelGuard NanoPhotometer ${ }^{\mathrm{TM}}$, IMPLEN Germany (http://www.implen.de). For the OneStep qPCR assays we applied 10-20 ng total RNA as template.

Assays for seven transcripts from the oxylipin pathway including assays for two lipoxgenase isoforms, one assay for a narbonin-like protein, and 6 assays of constitutive expressed tags (including a beta-tubulin assay - serving as invariably expressed (housekeeping) control) were developed based on SuperSAGE/ST-DGE. All assays were purchased from GenXPro GmbH, Frankfurt (see list in additional data $\mathrm{xy}$ ). Three replicates were performed per assay, averaged and compared to the expression level of the housekeeping gene. Fold-changes in expression levels were calculated using the $\Delta \Delta$-Ct method

\section{qRT-PCR expression profiling}

Quantitative real time PCR assays (qPCR assays) used in this study were designed and provided by GenXPro GmbH, Frankfurt, Germany. The qPCR assays were run as OneStep-qPCR with dual labelled probes (FAMBHQ) and ROX as passive reference. For each reaction of $15 \mu \mathrm{l} 10-20 \mathrm{ng}$ of total RNA was used as template. The OneStep-qPCR Mastermix (Clontech-Takara QTAQ-Mastermix) contains hot start Taq DNA polymerase, optimized reaction buffer, $5 \mathrm{mM} \mathrm{MgCl} 2$ (final concentration), 2.5 - $3.5 \mathrm{mM}$ nucleotides (including 200 $\mu \mathrm{M}$ dUTP) and reverse transcriptase combined with an RNAse inhibitor $[40 \mathrm{u} / \mu \mathrm{l}]$.

Specific primer were applied with a final concentration of $0.2-1.0 \mu \mathrm{M}$. The dual labelled probes had a final concentration of $0.016-0.08 \mu \mathrm{M}$. The PCR regime was done as following: i) Reverse transcription: $48^{\circ} \mathrm{C}$ for $20 \mathrm{~min}$, ii) Activation of the hot start Taq DNA polymerase at $95^{\circ} \mathrm{C}$ for $10 \mathrm{~min}$, and iii) 45 cycles with denaturing at $95^{\circ} \mathrm{C}$ for $15 \mathrm{sec}$, with an annealing/extension step at $60^{\circ} \mathrm{C}$ for one minute.

The amplification of the target genes at each cycle was monitored by qPCR probe-released fluorescence (FAM dye). The $\mathrm{Ct}$, defined as the PCR cycle at which a statistically significant increase of reporter fluorescence is first detected (10× above background), was used as a measure for the starting copy numbers of the target gene. Relative quantification of the amplified targets follows the comparative $\Delta \Delta \mathrm{CT}$ method. The amount of target, normalized to an endogenous reference and relative to a calibrator, is given by $2^{-\Delta \Delta C T}$ [92].

\section{Confirmation of expression profiles by microarray hybridization}

SuperSAGE expression profiles were confirmed by direct spotting of $26 \mathrm{bp}$ tags onto a 16K Agilent microarray (AGILENT TECHNOLOGIES, Santa Clara CA, USA) and hybridization against fluorophore-labeled cDNAs. Three thousand UniTags with different expression levels under salt, drought and cold stresses were selected [26]. Additionally, for each of the 3,000 selected tags, oligonucleotides with mismatches were spotted onto the microarray in three sets as follows: i) mismatch at position 7 ; ii) mismatches at positions 7 and 13, respectively, and iii) mismatches at positions 7, 13, and 20, respectively. Background was corrected with the Feature Extraction Software $^{\mathrm{TM}}$ (Agilent Technologies), subtracting the mismatch intensities for each spotted tag. Microarray design, spotting and hybridizations were carried out by ARRAY-ON GmbH, Gatersleben, Germany, according to the Agilent ${ }^{\mathrm{TM}}$ protocols (AGILENT TECHNOLOGIES, Santa Clara CA, USA).

\section{Sample preparation and fixation for in situ RT-PCR}

At full flowering stage, 10 plants were selected, of which 5 were exposed to salinity $(25 \mathrm{mM} \mathrm{NaCl})$ for $2 \mathrm{~h}$. Root nodules of $5 \mathrm{~mm}$ length were immediately harvested from the non-stressed and the salt-treated plants separately and thoroughly washed with DEPC (diethyl pyrocarbonate) treated water, then fixed in freshly prepared PFA [2\% (v/v) paraformaldehyde, 45\% (v/v) ethanol and $5 \%(\mathrm{v} / \mathrm{v})$ acetic acid] and stored overnight at $4{ }^{\circ} \mathrm{C}$. Fixed nodules were extensively washed with four changes of

Table 7 Ascorbate peroxidase (APX) gene-specific primer sequences for in situ RT-PCR

\begin{tabular}{lll}
\hline Gene & Forward primer & Reverse primer \\
\hline APX1 & 5'-ATCCTCTCATTTTGACAACTC-3' & 5'-ACTTTGAGTGACCCTGTATTC-3' \\
APX2 & 5'-ATCCTCTCATTाTGACAACTC-3' & 5'-TाTCTTTCTTGTGATCCTCT-3' \\
\hline
\end{tabular}


DEPC-treated water over $30 \mathrm{~min}(2 \times 5 \mathrm{~min}$ and $2 \times 10$ min) with agitation to remove PFA. Thereafter, the nodules were included in low melting $9 \%(\mathrm{~m} / \mathrm{v})$ agarose dissolved in filtered phosphate-buffered saline (PBS; 5 $\left.\mathrm{mM} \mathrm{Na}{ }_{2} \mathrm{HPO} 4,300 \mathrm{mM} \mathrm{NaCl}, \mathrm{pH} 7.5\right)$. The nodules in agarose blocs were cut into $50 \mu \mathrm{m}$ thick slices using a microtome. The resulting sections were collected into small tubes containing $0.5 \mathrm{ml}$ of DEPC-treated water and freed from residual agarose by three washes with DEPC-treated water heated to $60^{\circ} \mathrm{C}$.

For reverse transcription, the fixed sections were transferred to PCR tubes and incubated in $40 \mu \mathrm{l}$ R mix [RT 1X Reaction Buffer (50 mM Tris-HCl, pH 8.3, $75 \mathrm{mM} \mathrm{KCl}, 3 \mathrm{mM} \mathrm{MgCl}$, $10 \mathrm{mM} \mathrm{DTT}$ ) (Promega, Madison, WI, USA); $0.31 \mathrm{mM} \mathrm{dNTP}$ and $0.75 \mu \mathrm{M}$ genespecific reverse primer. Sequences deposited in Table 7. The samples were then heated to $65^{\circ} \mathrm{C}$ for $5 \mathrm{~min}$, placed on ice for $2 \mathrm{~min}$, then Moloney murine leukemia virus (M-MLV) reverse transcriptase $\mathrm{H}(-)$ (Promega) added to each sample to a final concentration of $5 \mathrm{U} \cdot \mu^{-1}$, and samples were incubated at $42^{\circ} \mathrm{C}$ for $1 \mathrm{~h}$.

After reverse transcription, the RT mix was removed, and the samples were washed three times each with $100 \mu \mathrm{l}$ DEPC-treated water. After removing the last wash, $40 \mu \mathrm{l}$ of of PCR mix [1× PCR buffer, Invitrogen, Carlsbad, CA, USA), $1.5 \mathrm{mM} \mathrm{MgCl}_{2}, 0.2 \mathrm{mM}$ of each $\mathrm{dNTP}, 0.25 \mu \mathrm{M}$ each of the gene-specific primer pair, $0.25 \mathrm{nM}$ digoxigenin-11-2'-deoxyuridine 5'-triphosphate (Dig-11-dUTP; Roche Diagnostics, Mannheim, Germany) and 1 U Taq DNA Polymerase (Invitrogen)] were added. Thermocycling was performed at $95^{\circ}$ for $3 \mathrm{~min}$ and 30 cycles $\left(95^{\circ} \mathrm{C}\right.$ for $30 \mathrm{~s} ; 55^{\circ} \mathrm{C}$ for $30 \mathrm{~s} ; 72^{\circ} \mathrm{C}$ for $45 \mathrm{~s}, 72^{\circ} \mathrm{C}$ for $2 \mathrm{~min}$ ) for all the genes. Negative controls (no-RT) were prepared omitting the reverse transcription step. In this case, the samples were put in $40 \mu \mathrm{l}$ of DEPC-treated water during the RT step, and subsequently processed as the other samples.

For the detection of the amplified cDNA, the PCR mix was removed after amplification, and the samples were washed three times each for $10 \mathrm{~min}$ in $200 \mu \mathrm{l}$ PBS under gentle agitation, and then incubated in $100 \mu \mathrm{l}$ blocking solution (2\% BSA in PBS) with $0.3 \%$ Triton for 30 min under gentle agitation in darkness at $37^{\circ} \mathrm{C}$.

Then the blocking solution was removed and replaced by $100 \mu \mathrm{l}$ of alkaline phosphatase-conjugated anti-dioxygenin-Fab fragment (Roche Diagnostics) diluted 1:1000 in $2 \%$ BSA. The samples were incubated at room temperature for $1 \mathrm{~h} 30 \mathrm{~min}$ and then washed three times for $10 \mathrm{~min}$ in PBS to remove excess antibody. Detection of alkaline phosphatase was carried out using the ELF-97 (enzyme-labeled fluorescent) endogenous phosphatase detection kit (Molecular Probes, Leiden, The Netherlands). The ELF substrate was diluted 1:40 in the alkaline detection buffer (Molecular Probes, Leiden,
The Netherlands), vigorously shaken, and then filtered through a $0.22-\mu \mathrm{m}$ filter (Millex ${ }^{\circledR}-\mathrm{GV}$, Millipore, Bedford, USA) to remove any aggregates of the substrate formed during storage. Samples were incubated in $20 \mu \mathrm{l}$ ELF substrate-buffer solution in the dark for $20 \mathrm{~min}$, then washed $3 \times 1$ min with wash buffer (PBS with $25 \mathrm{mM}$ EDTA and $5 \mathrm{mM}$ levamisole, $\mathrm{pH}$ 8.0) before the samples were mounted. Observations were made with an Olympus BX61 ${ }^{\circledR}$ microscope equipped with an epifluorescence condenser, a Hoechst/DAPI filter set and a color view camera.

\section{Additional material}

Additional file 1: Main data matrix with UniTags annotations and expression ratios. Sequences of UniTags-homologous chickpea ESTs. Microarray profiles from spotted UniTags.

Additional file 2: GSR over-representation analysis results. Raw data from each GSR independent analysis including lists of represented genes per GO term.

Additional file 3: Potential new-uncharacterized transcripts (genes) showing high salt stress induction in chickpea roots and nodules.

\section{Acknowledgements}

The authors thank Ruth Jüngling, University of Frankfurt, for technical advice, and the Array-On team for expert help with design of the microarrays. Work of the authors was supported by a grant from the Aquarhiz project (INCOCT-2004-509115) to GK, grants from the Grain Legumes project (Food-CT-

2004-506223) to GK and GenXPro GmbH, and from DFG to GK (Ka 332/22-1)

\section{Author details}

${ }^{1}$ Molecular BioSciences, Biocenter, Johann Wolfgang Goethe University, Maxvon-Laue-Str. 9, D-60439 Frankfurt am Main, Germany. ${ }^{2}$ GenXPro GmbH, Frankfurt Innovation Center FIZ Biotechnology, Altendörferallee 3, D-60438 Frankfurt am Main, Germany. ${ }^{3}$ Soil Symbiosis and Environment, INRA, 1 place Viala, 34060 Montpellier-Cedex, France. ${ }^{4}$ Molecular Ecology Laboratory, Department of Botany, Jamia Hamdard University, New Delhi, India. ${ }^{5}$ Estación Experimental del Zaidín, CSIC, C/Profesor Albareda, 1, 18008Granada, Spain. ${ }^{6}$ Unité de Recherche en Légumineuses, INRA-URLEG, 17 Rue Sully, 21000 Dijon, France.

\section{Authors' contributions}

$\mathrm{CM}$ and BR generated the SuperSAGE libraries and analyzed the obtained profiles. RH, FK and DS generated the $33^{\prime}$ and 5'-RACE sequences and designed the primers for QRT-PCR probes. MZ, JJD, and LA grew INRAT-93 in hydro-aeroponics for biological replications, as well as developed and conducted in situ PCR assays. GK and PW developed the experimental strategy, and were responsible for the preparation of the manuscript. All authors of the present work have read and approved the final manuscript.

\section{Competing interests}

The authors declare that they have no competing interests.

Received: 27 July 2010 Accepted: 14 February 2011 Published: 14 February 2011

\section{References}

1. Boyer JS: Plant Productivity and Environment. Science 1982, 218:443-448.

2. Ghollarata M, Raiesi $F$ : The adverse effects of soil salinization on the growth of Trifolium alexandrinum L. and associated microbial and biochemical properties in a soil from Iran. Soil Biol and Biochem 2007, 39:1699-1702.

3. Johnson N, Revenga C, Echeverria J: Ecology. Managing water for people and nature. Science 2001, 292:1071-1072. 
4. Gleick PH: Global freshwater resources: soft-path solutions for the 21st century. Science 2003, 302:1524-1528.

5. Millan T, Clarke H, Siddique K, Buhariwalla H, Gaur P, Kumar J, Gil J, Kahl G, Winter P: Chickpea molecular breeding: New tools and concepts. Euphytica 2006, 147:81-103.

6. Boudsocq M, Lauriere C: Osmotic signaling in plants: multiple pathways mediated by emerging kinase families. Plant Physiol 2005, 138:1185-1194.

7. Zhu JK: Salt and drought stress signal transduction in plants. Annu Rev Plant Biol 2002, 53:247-273.

8. Moller IM: Plant mitochondria and oxidative stress: Electron Transport, NADPH Turnover, and Metabolism of Reactive Oxygen Species. Annu Rev Plant Physiol Plant Mol Biol 2001, 52:561-591.

9. Apel K, Hirt H: Reactive oxygen species: metabolism, oxidative stress, and signal transduction. Annu Rev Plant Biol 2004, 55:373-399.

10. Cheng NH, Pittman JK, Zhu JK, Hirschi KD: The protein kinase SOS2 activates the Arabidopsis $\mathrm{H}(+) / \mathrm{Ca}(2+)$ antiporter $\mathrm{CAX} 1$ to integrate calcium transport and salt tolerance. J Biol Chem 2004, 279:2922-2926.

11. Gong Z, Koiwa H, Cushman MA, Ray A, Bufford D, Kore-eda S, Matsumoto TK, Zhu J, Cushman JC, Bressan RA, Hasegawa PM: Genes That Are Uniquely Stress Regulated in Salt Overly Sensitive (sos) Mutants. Plant Physiol 2001, 126:363-375.

12. Liu J, Ishitani M, Halfter U, Kim CS, Zhu JK: The Arabidopsis thaliana SOS2 gene encodes a protein kinase that is required for salt tolerance. Proceed Nat Acad Sci USA 2000, 97:3730-3734.

13. Sanchez-Barrena MJ, Martinez-Ripoll M, Zhu JK, Albert A: SOS3 (salt overly sensitive 3) from Arabidopsis thaliana: expression, purification, crystallization and preliminary X-ray analysis. Acta Crystallog D 2004, 60:1272-1274.

14. Teige M, Scheikl E, Eulgem T, Doczi R, Ichimura K, Shinozaki K, Dangl JL, Hirt H: The MKK2 pathway mediates cold and salt stress signaling in Arabidopsis. Mol Cell 2004, 15:141-152.

15. Klimecka M, Muszynska G: Structure and functions of plant calciumdependent protein kinases. Acta Biochim Pol 2007.

16. Romeis T, Ludwig AA, Martin R, Jones JD: Calcium-dependent protein kinases play an essential role in a plant defence response. EMBO J 2001, 20:5556-5567.

17. Saijo Y, Kinoshita N, Ishiyama K, Hata S, Kyozuka J, Hayakawa T, Nakamura T, Shimamoto K, Yamaya T, Izui K: A Ca(2+)-dependent protein kinase that endows rice plants with cold- and salt-stress tolerance functions in vascular bundles. Plant Cell Physiol 2001, 42:1228-1233.

18. Gadjev I, Vanderauwera S, Gechev TS, Laloi C, Minkov IN, Shulaev V, Apel K, Inze D, Mittler R, Van Breusegem F: Transcriptomic footprints disclose specificity of reactive oxygen species signaling in Arabidopsis. Plant Physiol 2006, 141:436-445.

19. Mantri NL, Ford R, Coram TE, Pang EC: Transcriptional profiling of chickpea genes differentially regulated in response to high-salinity, cold and drought. BMC Genomics 2007, 8:303.

20. Soussi M, Santamaria M, Ocana A, Lluch C: Effects of salinity on protein and lipopolysaccharide pattern in a salt-tolerant strain of Mesorhizobium ciceri. J Appl Microbiol 2001, 90:476-481.

21. Varshney RK, Hiremath PJ, Lekha P, Kashiwagi J, Balaji J, Deokar AA, Vadez V, Xiao $Y$, Srinivasan R, Gaur PM, et al: A comprehensive resource of droughtand salinity-responsive ESTs for gene discovery and marker development in chickpea (Cicer arietinum L.). BMC Genomics 2009, 10:523.

22. Silva APM, De Souza JES, Galante PAF, Riggins GJ, De Souza SJ, Camargo AA: The impact of SNPs on the interpretation of SAGE and MPSS experimental data. Nucl Acids Res 2004, 32:6104-6110.

23. Altschul SF, Gish W, Miller W, Myers EW, Lipman DJ: Basic local alignment search tool. J Mol Biol 1990, 215:403-410.

24. Coemans B, Matsumura H, Terauchi R, Remy S, Swennen R, Sagi L: SuperSAGE combined with PCR walking allows global gene expression profiling of banana (Musa acuminata), a non-model organism. Theor Appl Genet 2005, 111:1118-1126.

25. Takeda N, Okamoto S, Hayashi M, Murooka Y: Expression of LjENOD40 Genes in Response to Symbiotic and Non-symbiotic Signals: LjENOD40-1 and LjENOD40-2 are Differentially Regulated in Lotus japonicus. Plant Cell Physiol 2005, 46:1291-1298.

26. Gillis J, Mistry M, Pavlidis P: Gene function analysis in complex data sets using ErmineJ. Nat Protoc 5:1148-1159.

27. Del Rio LA, Corpas FJ, Sandalio LM, Palma JM, Gomez M, Barroso JB: Reactive oxygen species, antioxidant systems and nitric oxide in peroxisomes. J Exp Bot 2002, 53:1255-1272.
28. Aydi S, Drevon JJ, Abdelly C: Effect of salinity on root-nodule conductance to the oxygen diffusion in the Medicago truncatulaSinorhizobium meliloti symbiosis. Plant Physiol Biochem 2004, 42:833-840.

29. Eckardt NA: Oxylipin signaling in plant stress responses. Plant Cell 2008, 20:495-497.

30. Howe GA, Schilmiller AL: Oxylipin metabolism in response to stress. Curr Opin Plant Biol 2002, 5:230-236.

31. Schaller A, Stintzi A: Enzymes in jasmonate biosynthesis - structure, function, regulation. Phytochemistry 2009, 70:1532-1538.

32. Molina C, Rotter B, Horres R, Udupa SM, Besser B, Bellarmino L, Baum M Matsumura H, Terauchi R, Kahl G, Winter P: SuperSAGE: the drought stressresponsive transcriptome of chickpea roots. BMC Genomics 2008, 9:553.

33. Matsumura H, Bin Nasir KH, Yoshida K, Ito A, Kahl G, Kruger DH, Terauchi R: SuperSAGE array: the direct use of 26-base-pair transcript tags in oligonucleotide arrays. Nat Methods 2006, 3:469-474.

34. Fizames C, Munos S, Cazettes C, Nacry P, Boucherez J, Gaymard F, Piquemal D, Delorme V, Commes T, Doumas P, et al: The Arabidopsis root transcriptome by serial analysis of gene expression. Gene identification using the genome sequence. Plant Physiol 2004, 134:67-80.

35. Poroyko V, Hejlek LG, Spollen WG, Springer GK, Nguyen HT, Sharp RE, Bohnert $\mathrm{HJ}$ : The maize root transcriptome by serial analysis of gene expression. Plant Physiol 2005, 138:1700-1710.

36. Kim YC, Jung YC, Xuan Z, Dong H, Zhang MQ, Wang SM: Pan-genome isolation of low abundance transcripts using SAGE tag. FEBS Lett 2006, 580:6721-6729.

37. Holland MJ: Transcript abundance in yeast varies over six orders of magnitude. J Biol Chem 2002, 277:14363-14366.

38. Czechowski T, Bari RP, Stitt M, Scheible WR, Udvardi MK: Real-time RT-PCR profiling of over 1400 Arabidopsis transcription factors: unprecedented sensitivity reveals novel root- and shoot-specific genes. Plant I 2004, 38:366-379.

39. Boon K, Osorio EC, Greenhut SF, Schaefer CF, Shoemaker J, Polyak K, Morin PJ, Buetow KH, Strausberg RL, De Souza SJ, Riggins GJ: An anatomy of normal and malignant gene expression. Proc Natl Acad Sci USA 2002, 99:11287-11292.

40. Alexandrov N, Troukhan M, Brover V, Tatarinova T, Flavell R, Feldmann K: Features of Arabidopsis Genes and Genome Discovered using Fulllength cDNAs. Plant Molecular Biology 2006, 60:69-85.

41. Cheng J, Kapranov P, Drenkow J, Dike S, Brubaker S, Patel S, Long J, Stern D, Tammana H, Helt G, et al: Transcriptional maps of 10 human chromosomes at 5-nucleotide resolution. Science 2005, 308:1149-1154.

42. Kapranov P, Drenkow J, Cheng J, Long J, Helt G, Dike S, Gingeras TR: Examples of the complex architecture of the human transcriptome revealed by RACE and high-density tiling arrays. Genome Res 2005, 15:987-997.

43. Stamm S, Ben-Ari S, Rafalska I, Tang Y, Zhang Z, Toiber D, Thanaraj TA, Soreq H: Function of alternative splicing. Gene 2005, 344:1-20.

44. Wollerton MC, Gooding C, Wagner EJ, Garcia-Blanco MA, Smith CW Autoregulation of polypyrimidine tract binding protein by alternative splicing leading to nonsense-mediated decay. Mol Cell 2004, 13:91-100.

45. Narsai R, Howell KA, Millar AH, OToole N, Small I, Whelan J: Genome-Wide Analysis of mRNA Decay Rates and Their Determinants in Arabidopsis thaliana. Plant Cell 2007, 19:3418-3436.

46. Gechev TS, Van Breusegem F, Stone JM, Denev I, Laloi C: Reactive oxygen species as signals that modulate plant stress responses and programmed cell death. Bioessays 2006, 28:1091-1101.

47. Sanchez-Hernandez C, Martinez-Gallardo N, Guerrero-Rangel A, ValdesRodriguez S, Delano-Frier J: Trypsin and alpha-amylase inhibitors are differentially induced in leaves of amaranth (Amaranthus hypochondriacus) in response to biotic and abiotic stress. Physiol Plantarum 2004, 122:254-264.

48. Kawasaki S, Borchert C, Deyholos M, Wang H, Brazille S, Kawai K, Galbraith D, Bohnert HJ: Gene expression profiles during the initial phase of salt stress in rice. Plant Cell 2001, 13:889-905.

49. Kieliszewski MJ, Lamport DT: Extensin: repetitive motifs, functional sites, post-translational codes, and phylogeny. Plant J 1994, 5:157-172.

50. Tire C, De Rycke R, De Loose M, Inze D, Van Montagu M, Engler G: Extensin gene expression is induced by mechanical stimuli leading to local cell wall strengthening in Nicotiana plumbaginifolia. Planta 1994, 195:175-181. 
51. de Lorenzo L, Merchan F, Blanchet S, Megias M, Frugier F, Crespi M, Sousa C: Differential Expression of the TFIIIA Regulatory Pathway in Response to Salt Stress between Medicago truncatula Genotypes. Plant Physiol 2007, 145:1521-1532.

52. He XJ, Mu RL, Cao WH, Zhang ZG, Zhang JS, Chen SY: AtNAC2, a transcription factor downstream of ethylene and auxin signaling pathways, is involved in salt stress response and lateral root development. Plant J 2005, 44:903-916.

53. Popova OV, Ismailov SF, Popova TN, Dietz KJ, Golldack D: Salt-induced expression of NADP-dependent isocitrate dehydrogenase and ferredoxin-dependent glutamate synthase in Mesembryanthemum crystallinum. Planta 2002, 215:906-913.

54. Akamatsu S, Kamiya H, Yamashita N, Motoyoshi T, Goto-Yamamoto N, Ishikawa T, Okazaki N, Nishimura A: Effects of aldehyde dehydrogenase and acetyl-CoA synthetase on acetate formation in sake mash. J Biosci Bioeng 2000, 90:555-560.

55. Noji M, Saito M, Nakamura M, Aono M, Saji H, Saito K: Cysteine Synthase Overexpression in Tobacco Confers Tolerance to Sulfur-Containing Environmental Pollutants. Plant Physiol 2001, 126:973-980.

56. Attallah CV, Welchen E, Gonzalez DH: The promoters of Arabidopsis thaliana genes AtCOX17-1 and -2, encoding a copper chaperone involved in cytochrome c oxidase biogenesis, are preferentially active in roots and anthers and induced by biotic and abiotic stress. Physiol Plantarum 2007, 129:123-134

57. Grad LI, Lemire BD: Mitochondrial complex I mutations in Caenorhabditis elegans produce cytochrome c oxidase deficiency, oxidative stress and vitamin-responsive lactic acidosis. Human Mol Gen 2004, 13:303-314.

58. Costa JH, Jolivet $Y$, Hasenfratz-Sauder MP, Orellano EG, da Guia Silva Lima M, Dizengremel P, Fernandes de Melo D: Alternative oxidase regulation in roots of Vigna unguiculata cultivars differing in drought/ salt tolerance. J Plant Physiol 2007, 164:718-727.

59. Seltmann MA, Stingl NE, Lautenschlaeger JK, Krischke M, Mueller MJ, Berger S: Differential impact of lipoxygenase 2 and jasmonates on natural and stress-induced senescence in Arabidopsis. Plant Physiol 152:1940-1950.

60. Samuel M, Miles G, Ellis B: MAPK signalling and plant cell survival in response to oxidative environmental stress. Plant Responses to Air Pollution and Global Change 2005, 125-132.

61. Monks DE, Aghoram K, Courtney PD, DeWald DB, Dewey RE: Hyperosmotic stress induces the rapid phosphorylation of a soybean phosphatidylinositol transfer protein homolog through activation of the protein kinases SPK1 and SPK2. Plant Cell 2001, 13:1205-1219.

62. Koyama H, Ito T, Nakanishi T, Kawamura N, Sekimizu K: Transcription elongation factor S-II maintains transcriptional fidelity and confers oxidative stress resistance. Genes to Cells 2003, 8:779-788.

63. Singh $P$, Bhaglal $P$, Bhullar SS: Differential levels of wheat germ agglutinin (WGA) in germinating embryos of different wheat cultivars in response to osmotic stress. Plant Physiol Biochem 1996, 34:547-552.

64. Singh P, Chateerjee S, Pathania R, Bhullar SS: Enhanced wheat germ agglutinin accumulation in the germinating embryos of wheat (Triticum aestivum L.) appears to be a general stress response. Current Science 1999, 76:1140-1142.

65. Citterio S, Piatti S, Albertini E, Aina R, Varotto S, Barcaccia G: Alfalfa Mob1like proteins are involved in cell proliferation and are localized in the cell division plane during cytokinesis. Exp Cell Res 2006, 312:1050-1064.

66. Hasegawa PM, Bressan RA, Zhu JK, Bohnert HJ: Plant cellular and molecular responses to high salinity. Annu Rev Plant Physiol Plant Mol Biol 2000, 51:463-499.

67. Batelli G, Verslues PE, Agius F, Qiu Q, Fujii H, Pan S, Schumaker KS, Grillo S, Zhu JK: SOS2 promotes salt tolerance in part by interacting with the vacuolar H+-ATPase and upregulating its transport activity. Mol Cell Biol 2007, 27:7781-7790.

68. Gong D, Guo Y, Schumaker KS, Zhu JK: The SOS3 family of calcium sensors and SOS2 family of protein kinases in Arabidopsis. Plant Physiol 2004, 134:919-926.

69. Qiu QS, Guo Y, Dietrich MA, Schumaker KS, Zhu JK: Regulation of SOS1, a plasma membrane $\mathrm{Na}+\mathrm{H}+$ exchanger in Arabidopsisthaliana, by SOS2 and SOS3. Proc Natl Acad Sci USA 2002, 99:8436-8441.

70. Quan R, Lin H, Mendoza I, Zhang Y, Cao W, Yang Y, Shang M, Chen S, Pardo JM, Guo Y: SCABP8/CBL10, a Putative Calcium Sensor, Interacts with the Protein Kinase SOS2 to Protect Arabidopsis Shoots from Salt Stress. Plant Cell 2007, 19:1415-1431.
71. Mahajan S, Pandey GK, Tuteja N: Calcium- and salt-stress signaling in plants: shedding light on SOS pathway. Arch Biochem Biophys 2008, 471:146-158.

72. Martinez-Atienza J, Jiang X, Garciadeblas B, Mendoza I, Zhu JK, Pardo JM, Quintero FJ: Conservation of the SOS Salt Tolerance Pathway in Rice. Plant Physiol 2007, 143(2):1001-1012.

73. Tang RJ, Liu H, Bao Y, Lv QD, Yang L, Zhang HX: The woody plant poplar has a functionally conserved salt overly sensitive pathway in response to salinity stress. Plant Mol Biol 74:367-380.

74. Kumar G, Purty RS, Sharma MP, Singla-Pareek SL, Pareek A: Physiological responses among Brassica species under salinity stress show strong correlation with transcript abundance for SOS pathway-related genes. J Plant Physiol 2009, 166:507-520.

75. Gong Z, Koiwa H, Cushman MA, Ray A, Bufford D, Kore-eda S, Matsumoto TK, Zhu J, Cushman JC, Bressan RA, Hasegawa PM: Genes that are uniquely stress regulated in salt overly sensitive (sos) mutants. Plant Physiol 2001, 126:363-375.

76. Foyer $\mathrm{CH}$, Noctor $\mathrm{G}$ : Redox sensing and signalling associated with reactive oxygen in chloroplasts, peroxisomes and mitochondria. Physiol Plantarum 2003, 119:355-364.

77. Del Rio LA, Sandalio LM, Corpas FJ, Palma JM, Barroso JB: Reactive oxygen species and reactive nitrogen species in peroxisomes. Production, scavenging, and role in cell signaling. Plant Physiol 2006, 141:330-335.

78. Dat J, Vandenabeele S, Vranova E, Van Montagu M, Inze D, Van Breusegem F: Dual action of the active oxygen species during plant stress responses. Cell Mol Life Sci 2000, 57:779-795.

79. Becana M, Dalton DA, Moran JF, Iturbe-Ormaetxe I, Matamoros MAC, Rubio M: Reactive oxygen species and antioxidants in legume nodules. Physiol Plantarum 2000, 109:372-381.

80. Rubio MC, James EK, Clemente MR, Bucciarelli B, Fedorova M, Vance CP, Becana M: Localization of superoxide dismutases and hydrogen peroxide in legume root nodules. Mol Plant Microbe Interact 2004, 17:1294-1305.

81. Luo ZB, Janz D, Jiang X, Gobel C, Wildhagen H, Tan Y, Rennenberg H, Feussner I, Polle A: Upgrading root physiology for stress tolerance by ectomycorrhizas: insights from metabolite and transcriptional profiling into reprogramming for stress anticipation. Plant Physiol 2009, 151:1902-1917.

82. Beniwal RS, Langenfeld-Heyser R, Polle A: Ectomycorrhiza and hydrogel protect hybrid poplar from water deficit and unravel plastic responses of xylem anatomy. Environ Exp Botany 69:189-197.

83. Stoughton RB: Applications of DNA microarrays in biology. Annu Rev Biochem 2005, 74:53-82.

84. Erdogan F, Kirchner R, Mann W, Ropers HH, Nuber UA: Detection of mitochondrial single nucleotide polymorphisms using a primer elongation reaction on oligonucleotide microarrays. Nucleic Acids Res 2001, 29:E36.

85. Fan JB, Oliphant A, Shen R, Kermani BG, Garcia F, Gunderson KL, Hansen M, Steemers F, Butler SL, Deloukas $P$, et al: Highly parallel SNP genotyping Cold Spring Harb Symp Quant Biol 2003, 68:69-78.

86. Shen R, Fan JB, Campbell D, Chang W, Chen J, Doucet D, Yeakley J, Bibikova M, Wickham Garcia E, McBride C, et al: High-throughput SNP genotyping on universal bead arrays. Mutat Res 2005, 573:70-82.

87. Evans SJ, Watson SJ, Akil H: Evaluation of Sensitivity, Performance and Reproducibility of Microarray Technology in Neuronal Tissue. Integr Comp Biol 2003, 43:780-785.

88. Gingeras TR: Origin of phenotypes: Genes and transcripts. Genome Res 2007, 17:682-690.

89. L'Taief B, Sifi B, Zaman-Allah M, Drevon JJ, Lachaal M: Effect of salinity on root-nodule conductance to the oxygen diffusion in the Cicer arietinumMesorhizobium ciceri symbiosis. J Plant Physiol 2007, 164:1028-1036.

90. Lee HK, Braynen W, Keshav K, Pavlidis P: ErmineJ: tool for functional analysis of gene expression data sets. BMC Bioinformatics 2005, 6:269.

91. Sambrook J, Russell DW: Molecular cloning: a laboratory manual. 3 edition. Cold Spring Harbor, N.Y.: Cold Spring Harbor Laboratory Press; 2001.

92. Pfaffl MW: A new mathematical model for relative quantification in realtime RT-PCR. Nucleic Acids Res 2001, 29:e45.

doi:10.1186/1471-2229-11-31

Cite this article as: Molina et al:: The salt-responsive transcriptome of chickpea roots and nodules via deepSuperSAGE. BMC Plant Biology 2011 11:31. 